\title{
Melting, Solidification, Remelting, and Separation of Glass and Metal
}

\author{
Topical Report \\ January 1998
}

\author{
By: \\ M. A. Ebadian; R. C. Xin \\ Y.Z. Liu
}

Work Performed Under Contract No.: DE-FG21-95EW55094

For

U.S. Department of Energy Office of Fossil Energy

Federal Energy Technology Center

P.O. Box 880

Morgantown, West Virginia 26507-0880

in of Glass

RECEIVED

OCT 201998

OSTI

By

Florida International University

Hemispheric Center for Environmental Technology (HCET)

Center for Engineering \& Applied Sciences

10555 West Flagler Street

EAS-2100

Miami, Florida 33174

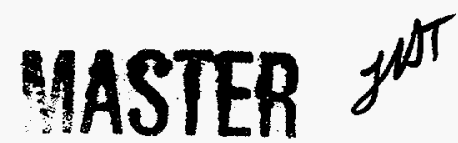




\section{Disclaimer}

This report was prepared as an account of work sponsored by an agency of the United States Government. Neither the United States Government nor any agency thereof, nor any of their employees, makes any warranty, express or implied, or assumes any legal liability or responsibility for the accuracy, completeness, or usefulness of any information, apparatus, product, or process disclosed, or represents that its use would not infringe privately owed rights. Reference herein to any specific commercial product, process, or service by trade name, trademark, manufacturer, or otherwise does not necessarily constitute or imply its endorsement, recommendation, or favoring by the United States Government or any agency thereof. The views and opinions of authors expressed herein do not necessarily state or reflect those of the United States Government or any agency thereof. 


\section{DISCLAIMER}

Portions of this document may be illegible electronic image products. Images are produced from the best available original document. 


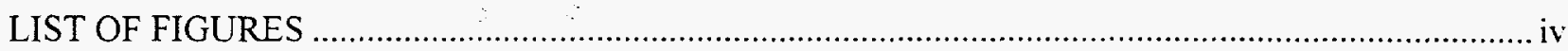

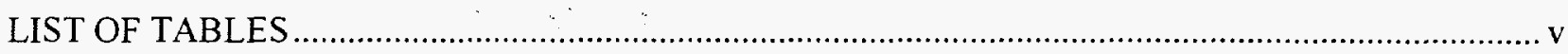

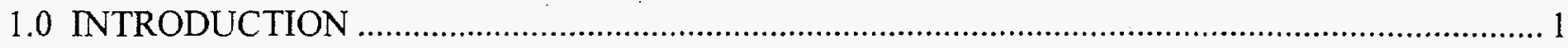

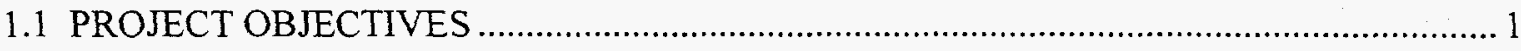

1.2 SUMMARY OF FY96 ACCOMPLISHMENTS ….......................................................... 2

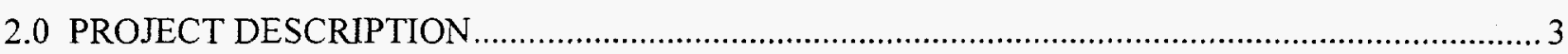

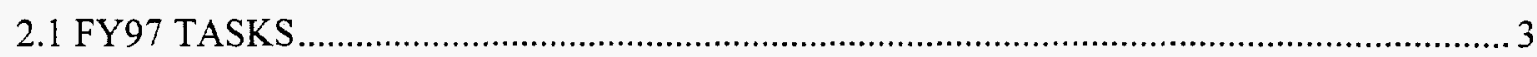

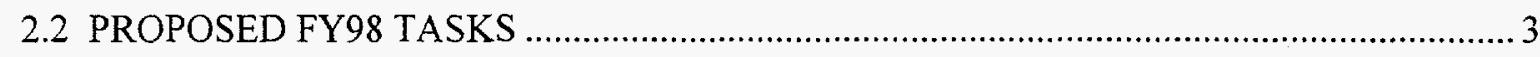

3.0 MELTING AND SOLIDIFICATION TEST RESULTS ........................................................ 5

3.1 EXPERIMENTAL AND MEASUREMENT SYSTEM …................................................... 5

3.2 MELTING AND SOLIDIFICATION OF STAINLESS STEEL AND

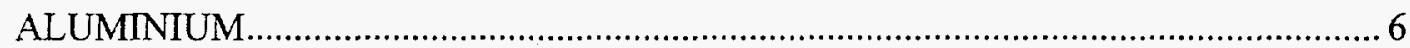

3.3 MELTING AND SंOLIDIFICATION OF GLASSES ................................................. 10

3.4 MELTING AND SOLIDIFICATION OF METAL AND GLASS MIXTURE .................... 11

4. SIMULATION TESTS OF LIQUID-LIQUID SEPARATION ................................................... 16

5. NUMERICAL MODELING OF METAL/GLASS PHASE SEPARATION....................................22

5.1 MATHEMATICAL MODEL AND NUMERICAL METHODS ….................................22

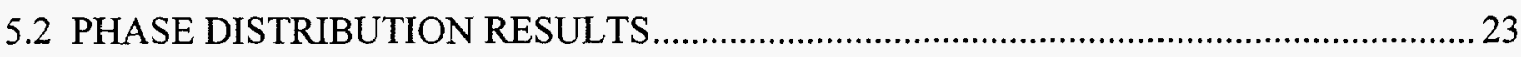

6. MOLTEN METAL/GLASS PHASE SEPARATION EXPERIMENTS ...........................................2 24

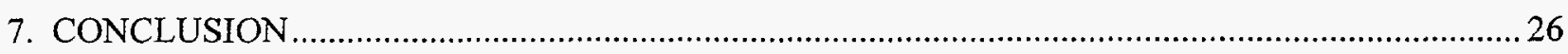

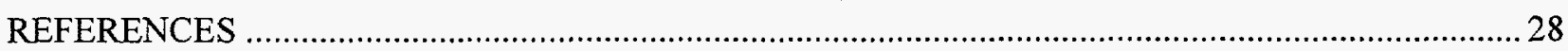

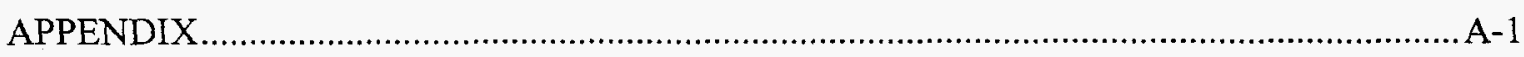




\section{LIST OF FIGURES}

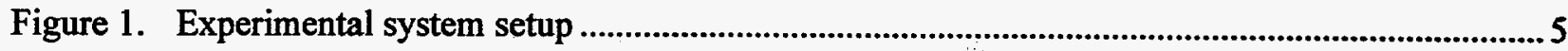

Figure 2. The temperature responses of a B-type thermocouple immerged in molten

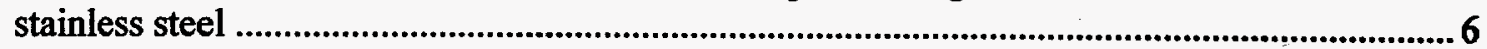

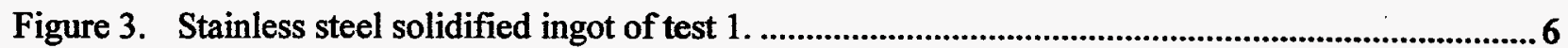

Figure 4. Temperature history of the solidification process of stainless steel in test 1 ..........................6

Figure 5. Temperature curves for different locations in the stainless steel solidification

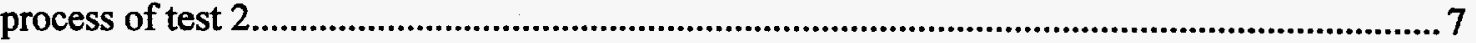

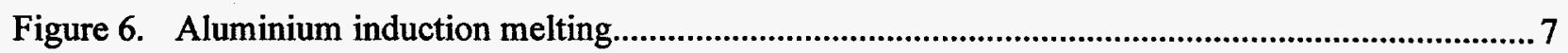

Figure 7. Magnetic elevation of aluminium induction melting. ..........................................................8

Figure 8. Temperature curves for the solidification of molten aluminium............................................. 8

Figure 9. Aluminium solidification temperature curves for a hot crucible-central-line....................... 9

Figure 10. Aluminium solidification temperature curves for a cool crucible-central

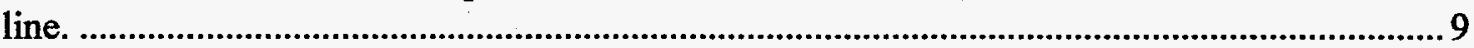

Figure 11. Aluminium solidification temperature curves a hot crucible—lateral locations...................... 10

Figure 12. Temperature history curves of SRS borosilicate glass melting..............................................10

Figure 13. Temperature history curve of SRS glass solidification. ........................................................ 11

Figure 14. The stainless steel and glass mixture solidified ingot. .......................................................... 11

Figure 15. Temperature curve for stainless steel and commercial borosilicate glass

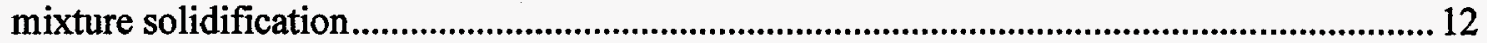

Figure 16. Temperature curve for stainless steel and SRS borosilicate glass mixture

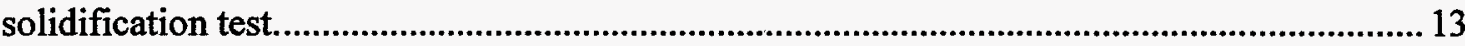

Figure 17. Temperature curve for stainless steel and mixed glass solidification test............................... 14

Figure 18. Temperature curves for two different locations during the stainless steel and

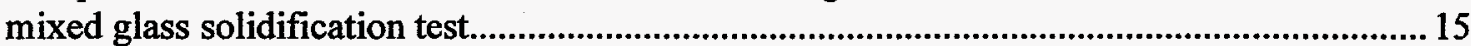

Figure 19. The turntable and demonstration setup with kerosene-water stationary ................................ 17

Figure 20. The interface shape of the kerosene-water system with a rotation speed of 155 rpm.

Figure 21. The interface shape of the kerosene-water system with a rotation speed of 285 rpm

Figure 22. Separation efficiency of CS separation simulation tests .................................................... 18

Figure 23. DCS simulation test setup and interface shapes
(a) and (b)
(c) and (d)...

Figure 24. Phase distribution and interface shapes for triangular separator

Figure 25. The suspension of kerosene in PLUMR .............................................................................20

Figure 26. The mid-stage of the suspension separation at five minutes ..............................................20 
Figure 27. The mid-stage of the suspension separation at ten minutes.

Figure 28. The final phase distribution of the suspension after rotation

Figure 29. Phase distribution and separation of liquid-liquid suspension using the cylindrical separator

Figure 30. Glass volume fraction distribution for the cases of $2 \%$ (left) and $5 \%$ (right) glass content with a rotating speed of $300 \mathrm{rpm}$.

Figure 31. Glass volume fraction distribution for the case of $10 \%$ glass content with rotating speeds of $150 \mathrm{rpm}$ (left) and $300 \mathrm{rpm}$ (right)

Figure 32. Flange crucible assembly

Figure 33. Molten metal/glass phase separation test setup 24

Figure 34. Final phase states after melting, rotating and solidification 25

Figure 35. Metal phase ingot and the interface shape $(150 \mathrm{rpm})$. 25

Figure 36. Free surface and interface shape. 25

\section{LIST OF TABLES}

Table 1. The Properties of the Simulated Liquids 16

Table 2. Viscosity of PLUMR. 


\subsection{INTRODUCTION}

Several kinds of mixed waste exist at various U.S. Department of Energy (DOE) sites. Vitrification is a particularly attractive technique for treating these wastes. Several hightemperature vitrification technologies have been developed for the treatment of a wide range of mixed waste types in both the low-level waste and transuranic (TRU) mixed waste categories currently in storage at DOE sites throughout the nation. These processes include the plasma hearth process, which is being developed by Science Applications International Corporation (SAIC), and the arc melter vitrification process, which is being developed at Idaho National Engineering Laboratory. The products of these processes are an oxide slag phase and a reduced metal phase. The metal phase has the potential to be recycled within the DOE Complex. Enhanced slag/metal separation methods are needed to support these processes. A separation method to obtain highly refined recycled metals is also needed for the radioactively contaminated scrap metal recycling processes. This research project, which began at the Hemispheric Center for Environmental Technology at Florida International University (FIU-HCET) in fiscal year 1996 (FY96), involves an experimental investigation of the melting, solidification, remelting, and separation of glass and metal and the development of an efficient separation technology. Two innovative separation technologies-differential centrifugal separation (DCS) and centrifugal separation (CS) - were proposed and conceptually designed in FY96. The melting, solidification, and phase separation tests were conducted in fiscal year 1997 (FY97).

There is an essential need for efficient extraction/separation devices for the various kinds of DOE liquid waste treatment processes. These processes include solvent extraction of radionuclides from aqueous tank waste; extraction and recovery of uranium, transuranics, and fission products from acidic high-level waste; cleanup and recycling of oil and chemical spills in water resources; liquid-liquid chemical extraction processes; and de-watering organic liquids. The conventional vessel-type separators have several disadvantages, such as large volume, low efficiency, and high cost. They do not meet the special needs of nuclear waste separation, remediation, and recycling activities considering the possibility of recontamination, hazardous material exposure, etc. Therefore, advanced separation apparatuses, featuring compact, effective, and in-line continuous operational modes, are desired for decontamination and decommissioning (D\&D) practices at DOE sites. The continuous separation simulation tests scheduled for FY98 may be helpful in developing an innovative liquid-liquid separator.

\subsection{PROJECT OBJECTIVES}

The ultimate goal of this project is to find an efficient way to separate the slag phase from the metal phase in the molten state. A basic knowledge of the thermal, transport, and metallurgical phenomena that occur in the melting and solidification of glass, metal, and their mixtures is the foundation of the development of the separation methods.

In association with this project, an innovative liquid-liquid extractor/separator will be developed to meet the need for efficient extraction/separation devices for the various DOE liquid waste treatment processes. 


\subsection{SUMMARY OF FY96 ACCOMPLISHMENTS}

This two-year project commenced in October 1995 (FY96). In the first fiscal year, the following tasks were accomplished.

- A literature review and an assessment of the baseline glass and metal separation technologies were performed. The results indicated that the baseline technology yields a high percentage of glass in the metal phase, requiring further separation.

- The main melting and solidification system setup was established. A number of melting and solidification tests were conducted.

- Temperature distribution, solidification patterns, and flow field in the molten metal pool were simulated numerically for the solidification processes of molten aluminum and iron steel.

- Initial designs of the laboratory-scale DCS and CS technologies were also completed. The principal demonstration separation units were constructed.

- An application for a patent for an innovative liquid-liquid separation technology was submitted and is pending. 


\subsection{PROJECT DESCRIPTION}

The purpose of this project is to investigate the melting and solidification characteristics of selected glasses, metals, and their mixtures and to develop new or improved technologies for glass/metal separation. The primary goals of this project are to:

- develop and implement measurement methods for metal and glass melting and solidification tests

- investigate the melting and solidification characteristics of glass, metals, and their mixtures

- perform simulation testing

- perform molten-state, high-temperature testing, and demonstrate the new or improved technologies.

\subsection{FY97 TASKS}

The following tasks were scheduled for completion in FY97:

1. Experimental investigation of the melting and solidification of metal, glass, and their mixtures to obtain the basic characteristics of the melting and solidification process and provide constructive information for separation technology development

2. Verification of the concepts used in the DCS and CS technologies by means of tests in lowtemperature environments using simulants

3. Improvements in the design of the DCS and CS techniques

4. Molten glass/metal phase separation tests

The following objectives were achieved:

1. Melting and solidification experiments for metal, glass, and their mixtures were conducted

2. Simulation tests for the DCS and CS technologies were completed

3. Numerical modeling of molten metal/glass phase distributions in rotating crucibles was completed

4. Molten glass/metal phase separation in a rotating furnace was studied

\subsection{PROPOSED FY98 TASKS}

There are three primary tasks for FY98

TASK 1. Perform additional molten state phase separation tests to investigate the effect of the rotating speed on the phase separation. A scanning electron microscope (SEM) will be used to analyze the results. 
TASK 2. Set up and conduct the continuous separation simulation tests to verify the proposed technology in continuous operating mode.

TASK 3. Depending on results and resources, the batch flowout separation demonstration setup will be completed and tested.

The project will be executed in the following stages. First, the molten metal/glass phase separation in a rotating crucible will be continued to investigate the effect of rotating speed on the phase separation. Second, based on the phase distribution and batch test results, a continuous operating experimental setup will be designed, fabricated, and set up to simulate the molten metal/glass centrifugal separation in continuous operating mode. Different parameter effects on the separation efficiency will be studied using this setup. 


\subsection{MELTING AND SOLIDIFICATION TEST RESULTS}

\subsection{EXPERIMENTAL AND MEASUREMENT SYSTEM}

The melting and solidification system, which includes a furnace, a computer-controlled data acquisition unit, a power unit, and a cooling unit for the power supply and an induction coil, is shown in Figure 1.

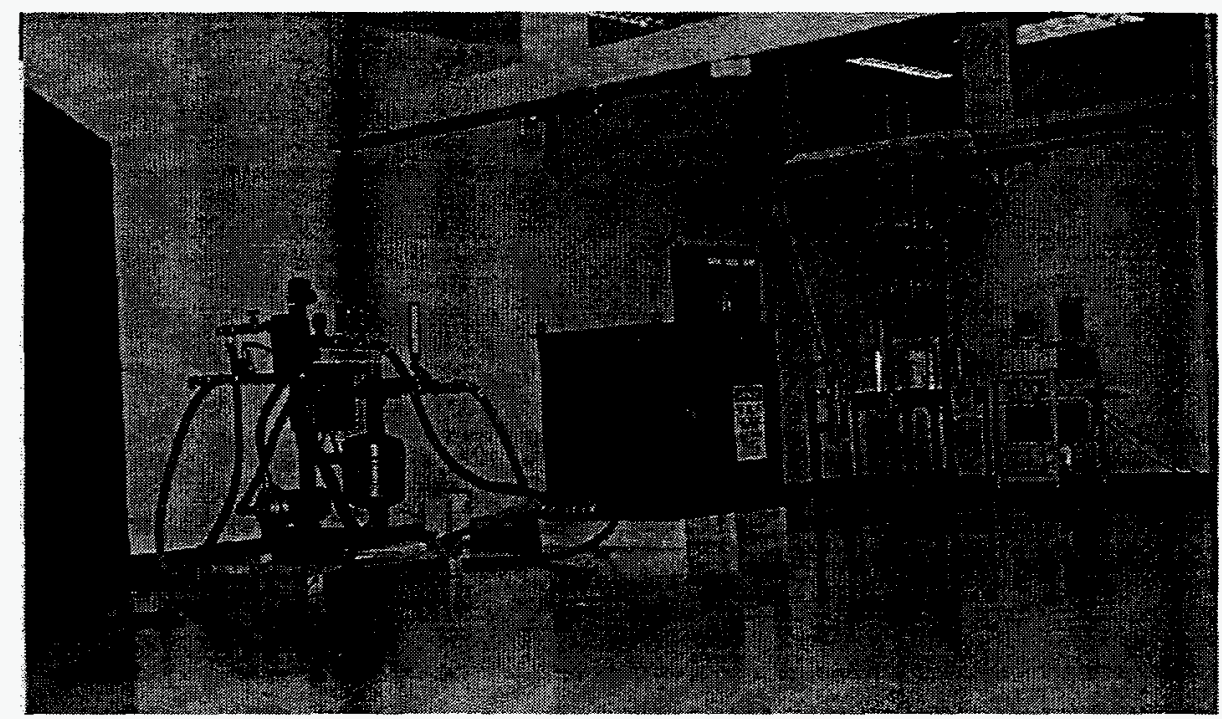

Figure 1. Experimental system setup.

In the solidification tests, the problem of how to measure the temperature of the molten stainless steel and aluminium during the solidification process has been solved. K-type and B-type thermocouples are used for temperature measurement in molten aluminium and stainless steel, respectively. The K-type thermocouples are protected by a cast iron tube. During measurement, a one-time-use quartz or ceramic thermocouple protection tube was used without thermocouple wire damage in the molten stainless steel solidification tests. So, the expensive B-type thermocouple wires can be used many times. When immersed in molten stainless steel, the thermocouple's response was recorded and is shown in Figure 2. 


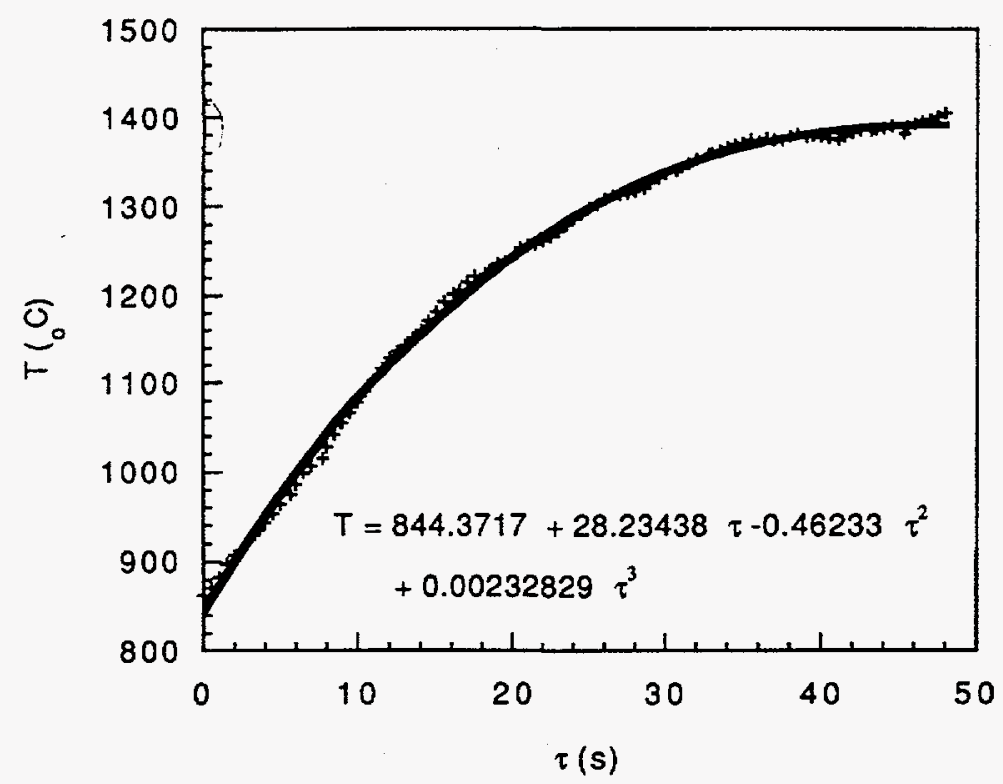

Figure 2. The temperature responses of a B-type thermocouple immerged in molten stainless steel.

\subsection{MELTING AND SOLIDIFICATION OF STAINLESS STEEL AND ALUMINIUM}

Several tests were conducted for the solidification of stainless steel, some of which were unsuccessful because of problems with the crucible or thermocouple. Two successful tests were conducted using the improved temperature measurement technique. The solidified ingot and temperature history of one location inside of the solidification region for the first test case are displayed in Figures 3 and 4, respectively.

Thermocouple Location

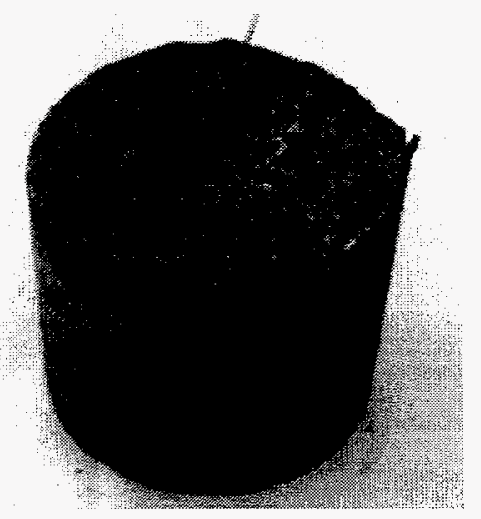

Figure 3. Stainless steel solidified ingot of test 1 .

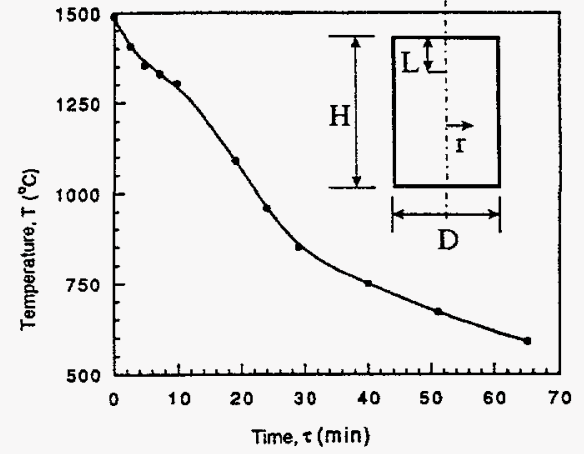

$H=6$ in.; $D=5$ in.; Locaton: $L=1.5$ in.; $r=0$

Figure 4. Temperature history of the solidification process of stainless steel in test 1. 
In the second test case, temperatures of two different locations were measured, and the temperature curves are shown in Figure 5. Solidification occurred at the top first, then at the bottom, and the temperature curves are similarly shaped.

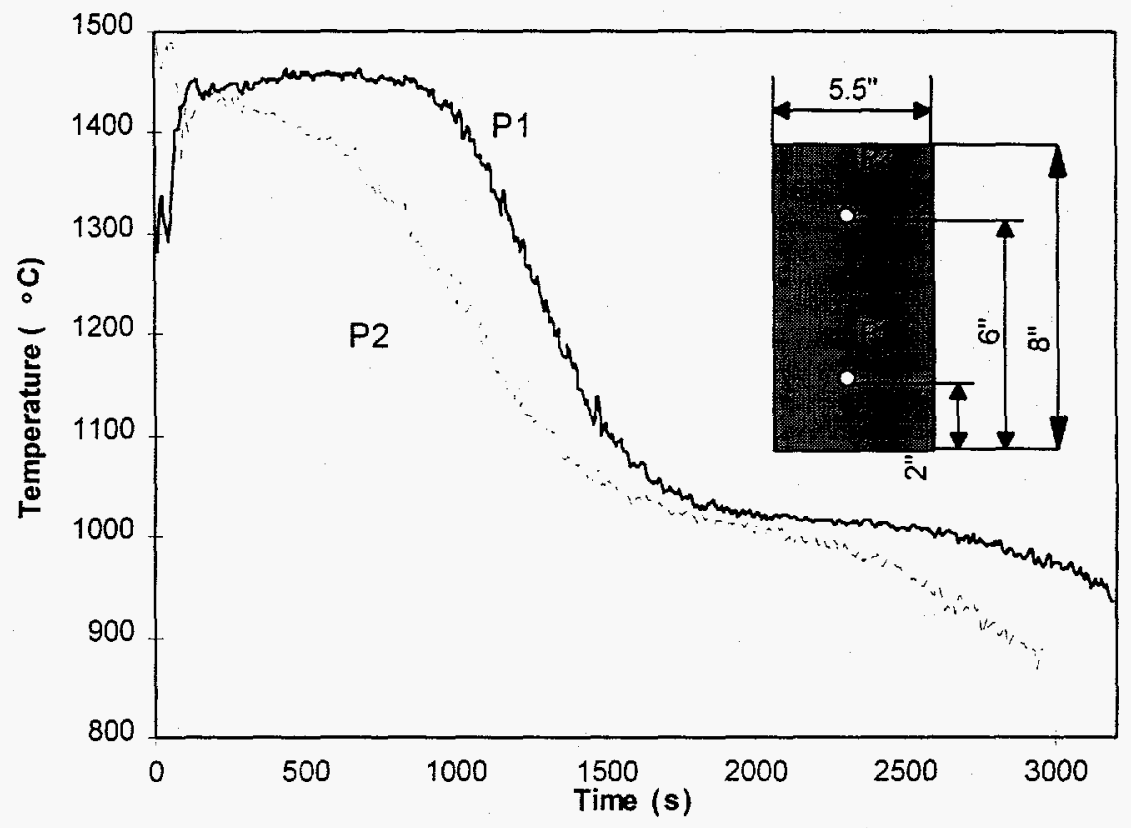

Figure 5. Temperature curves for different locations in the stainless steel solidification process of test 2.

Aluminium melting/solidification tests have been conducted. The melting temperature history is shown in Figure 6. During the melting of the aluminium, the magnetic elevation for the molten aluminium was observed to be cone shaped (Figure 7).

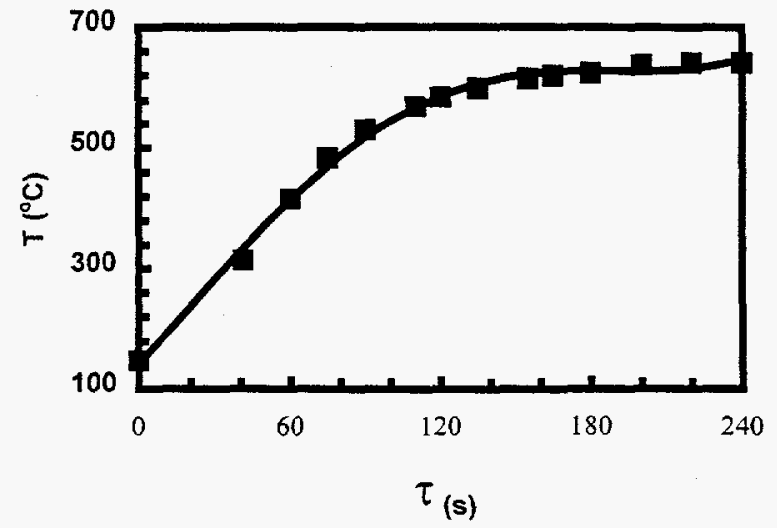

Figure 6. Aluminum induction melting temperature history. 


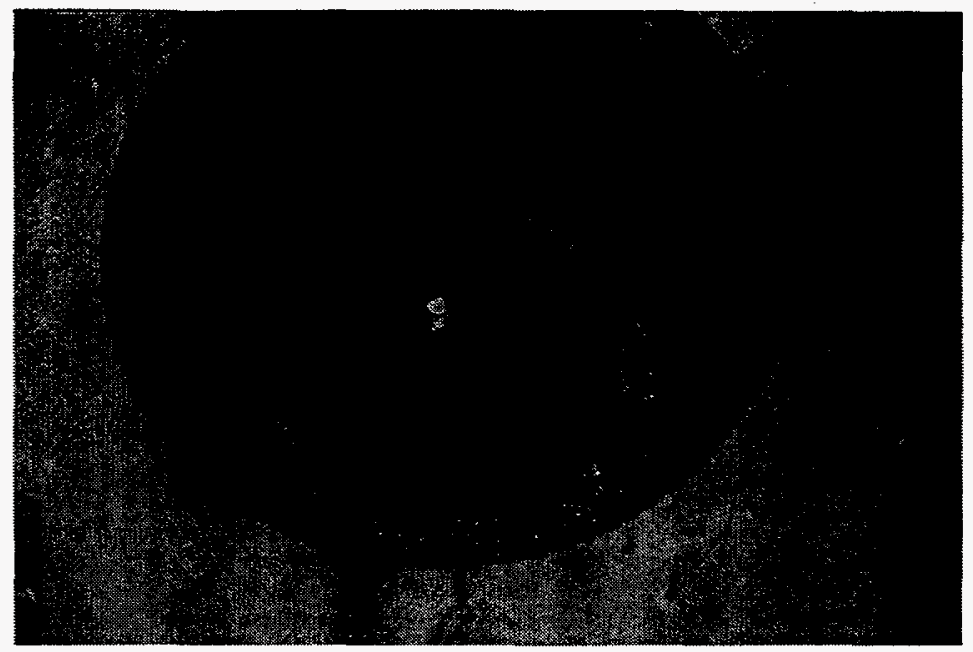

Figure 7. Magnetic elevation of aluminium induction melting.

The solidification temperature curves for two locations on the center-line are displayed in Figure 8. Heating, melting, and overheating stages can be obviously identified from the melting temperature history in Figure 8. The following can be observed from the figure: (1) the heating and melting rate is much faster than that of stainless steel melting; (2) the temperature is nearly uniform at different locations inside the solidified domain; (3) the convection, solidification, and conduction ranges can be observed.
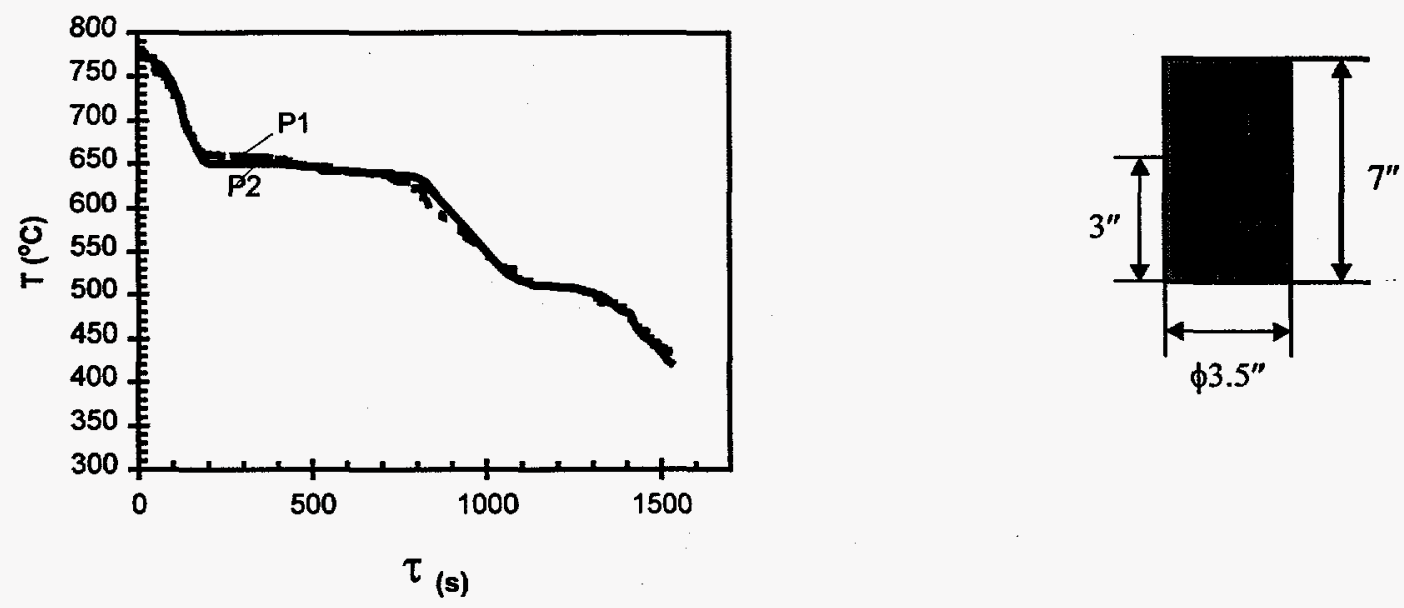

Figure 8. Temperature curves for the solidification of molten aluminium.

Some additional aluminium solidification tests have been conducted. Figures 9 through 11 show the results of temperature measurement for different conditions. Figures 9 and 10 show the temperatures for two locations on the centerline of aluminium solidification in a hot crucible (the 
melting crucible) and a cool crucible (into which molten stainless steel was poured), respectively. It is evident that the solidification rate is much faster in the cool crucible than in the hot crucible. Figure 11 shows the temperature histories of two points at the same height inside the crucible.

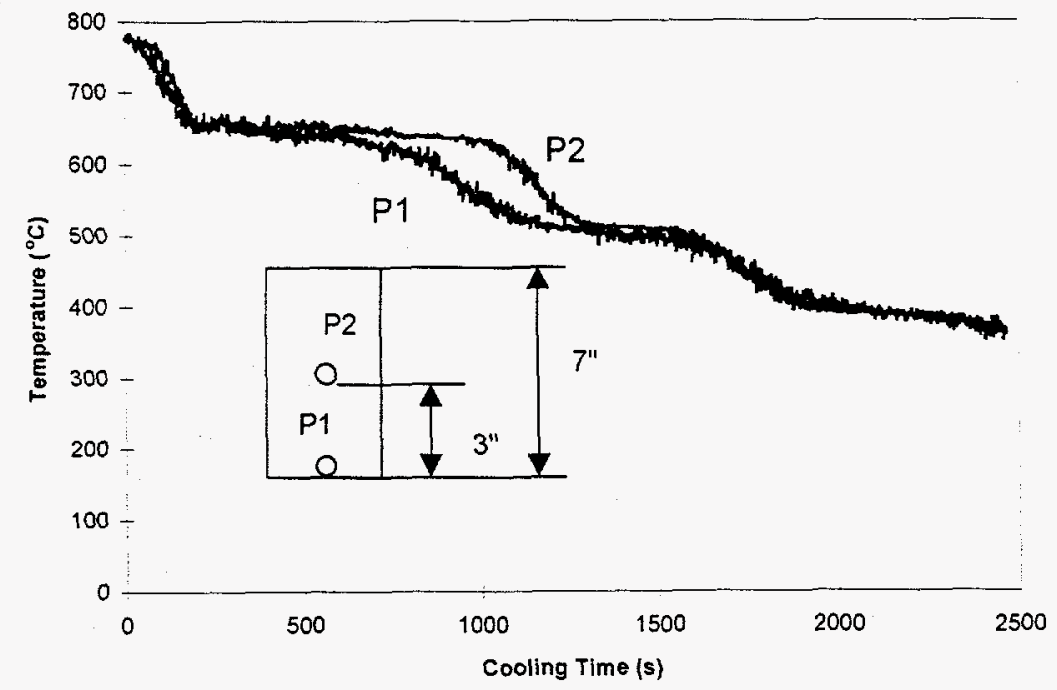

Figure 9. Aluminium solidification temperature curves for a hot crucible-central-line.

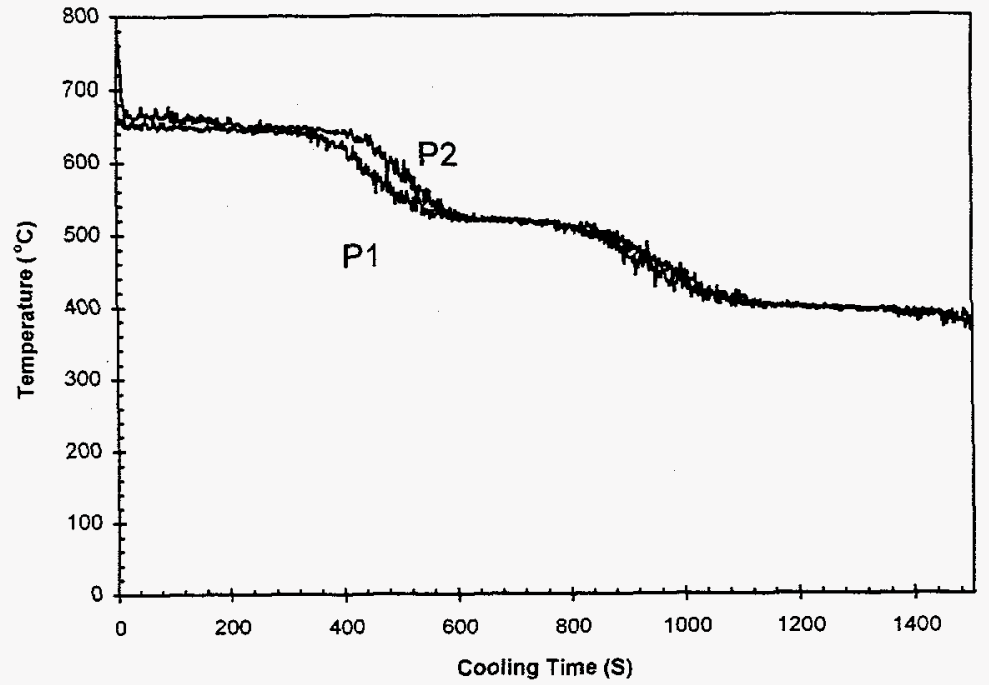

Figure 10. Aluminium solidification temperature curves for a cool crucible-central line. 


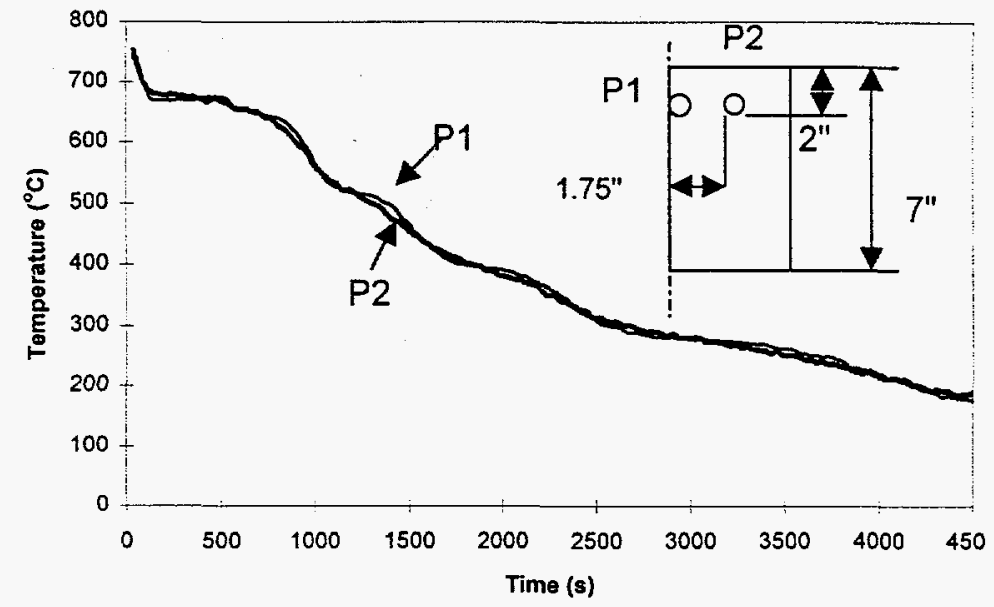

Figure 11. Aluminium solidification temperature curves for a hot crucible-lateral locations.

\subsection{MELTING AND SOLIDIFICATION OF GLASSES}

Some melting and solidification tests of pure glass were conducted in a graphite crucible. The molten commercial borosilicate glass was too sticky for temperature measurement. In the test of Savannah River Site (SRS) glass, the glass was melted completely and good flowability was observed. Temperature data were obtained and are displayed in Figures 12 and 13 for melting and solidification, respectively.

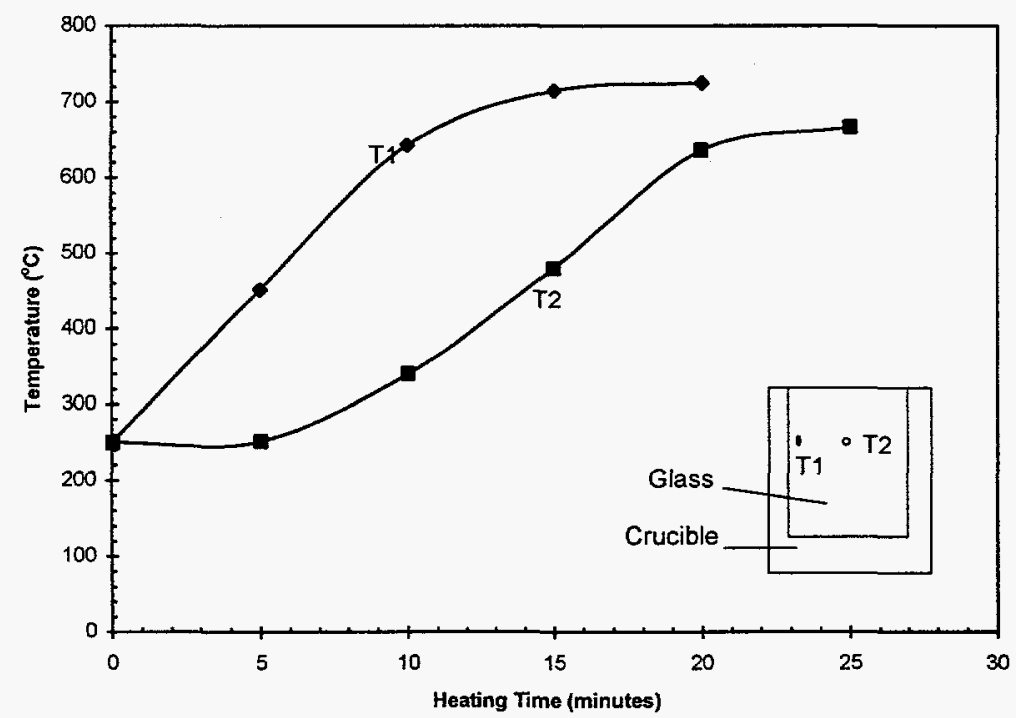

Figure 12. Temperature history curves of SRS borosilicate glass melting. 


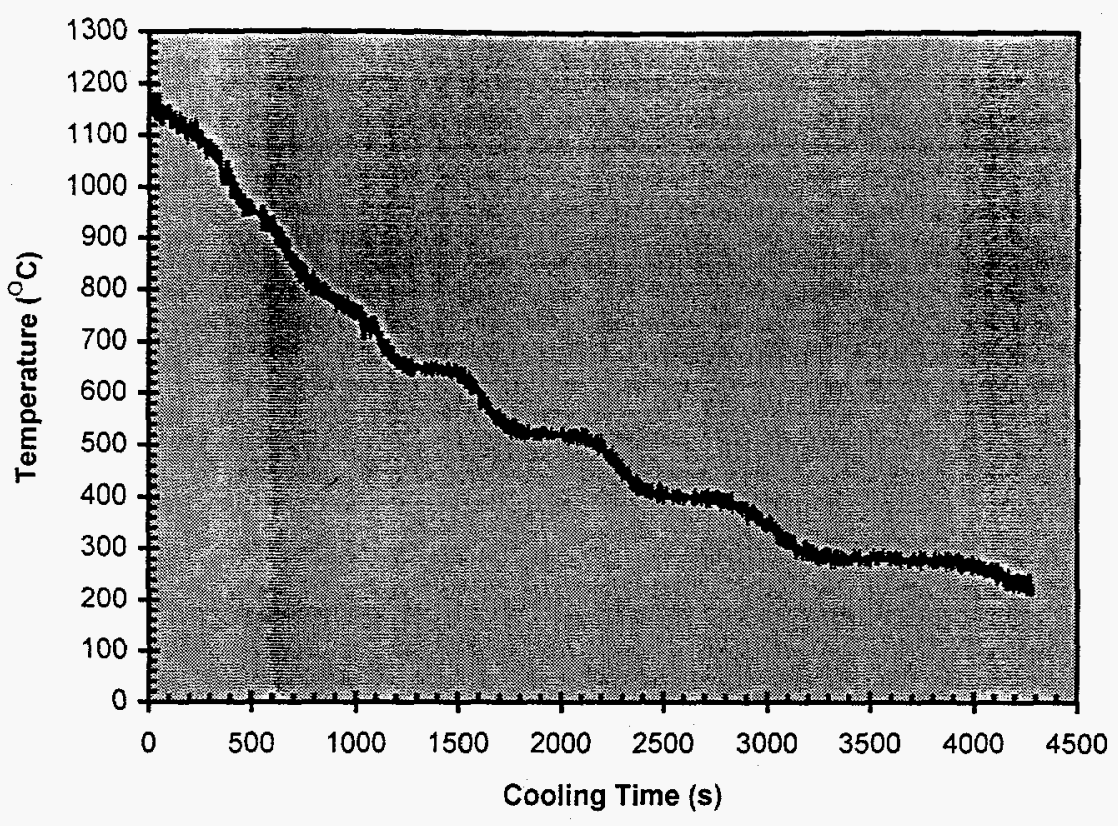

Figure 13. Temperature history curve of SRS glass solidification.

\subsection{MELTING AND SOLIDIFICATION OF METAL AND GLASS MIXTURE}

A total of six tests for solidification with stainless steel and glass phases were conducted. In the first two tests, the stainless steel and commercial borosilicate glass were used. Very good flowability of the molten stainless steel and very poor flowability of the molten glass were observed up to $1500^{\circ} \mathrm{C}$. The phase distribution was also observed. Figure 14 shows the solidified ingots.

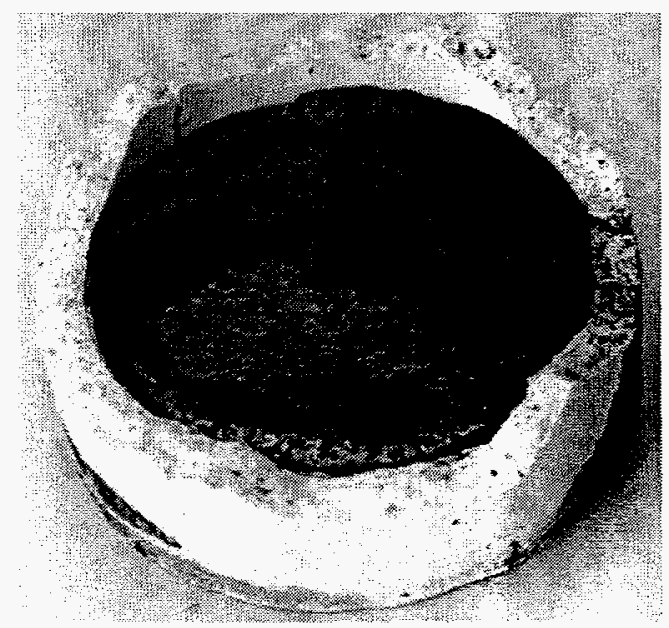

Test 1

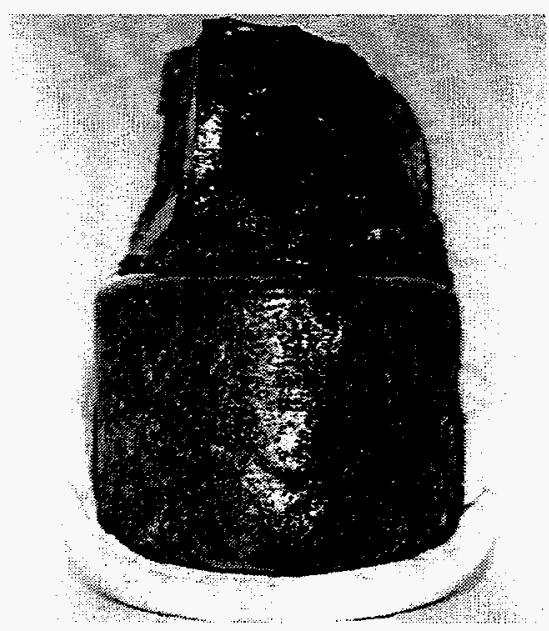

Test 2

Figure 14. The stainless steel and glass mixture solidified ingot. 
The third test for the stainless steel and commercial borosilicate glass mixture was performed. In this test, the glass was still very sticky and had a hard top surface even when the stainless steel was completely melted at $1500^{\circ} \mathrm{C}$. The thermocouple probe could not be placed correctly. Only some data from one thermocouple were recorded at the beginning of the test as shown in Figure 15. The fourth test was conducted for stainless steel and SRS borosilicate glass mixture. Because of the low melting temperature for this type of glass, it boiled before the stainless steel melted. Only the temperature inside the stainless steel was measured as shown in Figure 16.

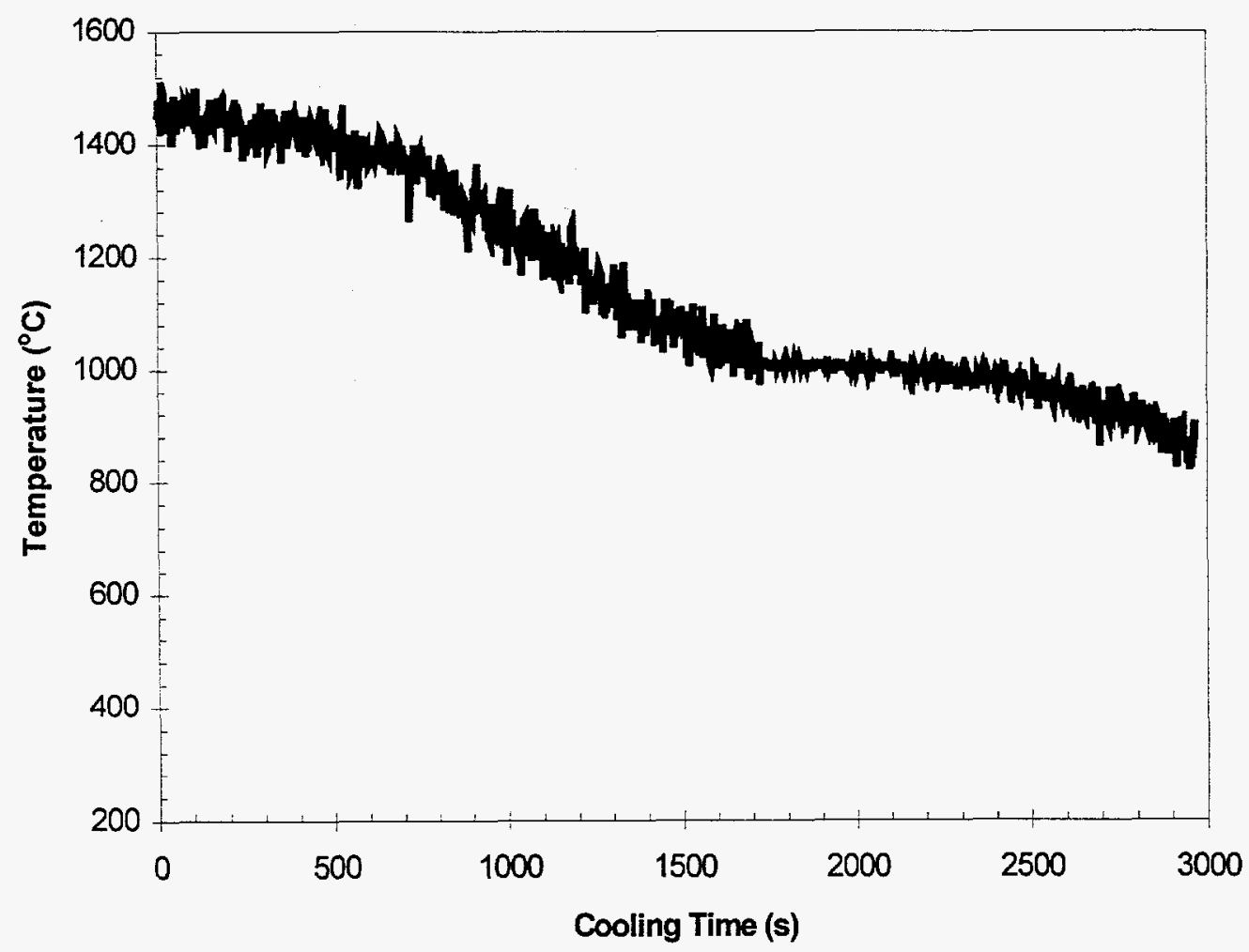

Figure 15. Temperature curve for stainless steel and commercial borosilicate glass mixture solidification. 


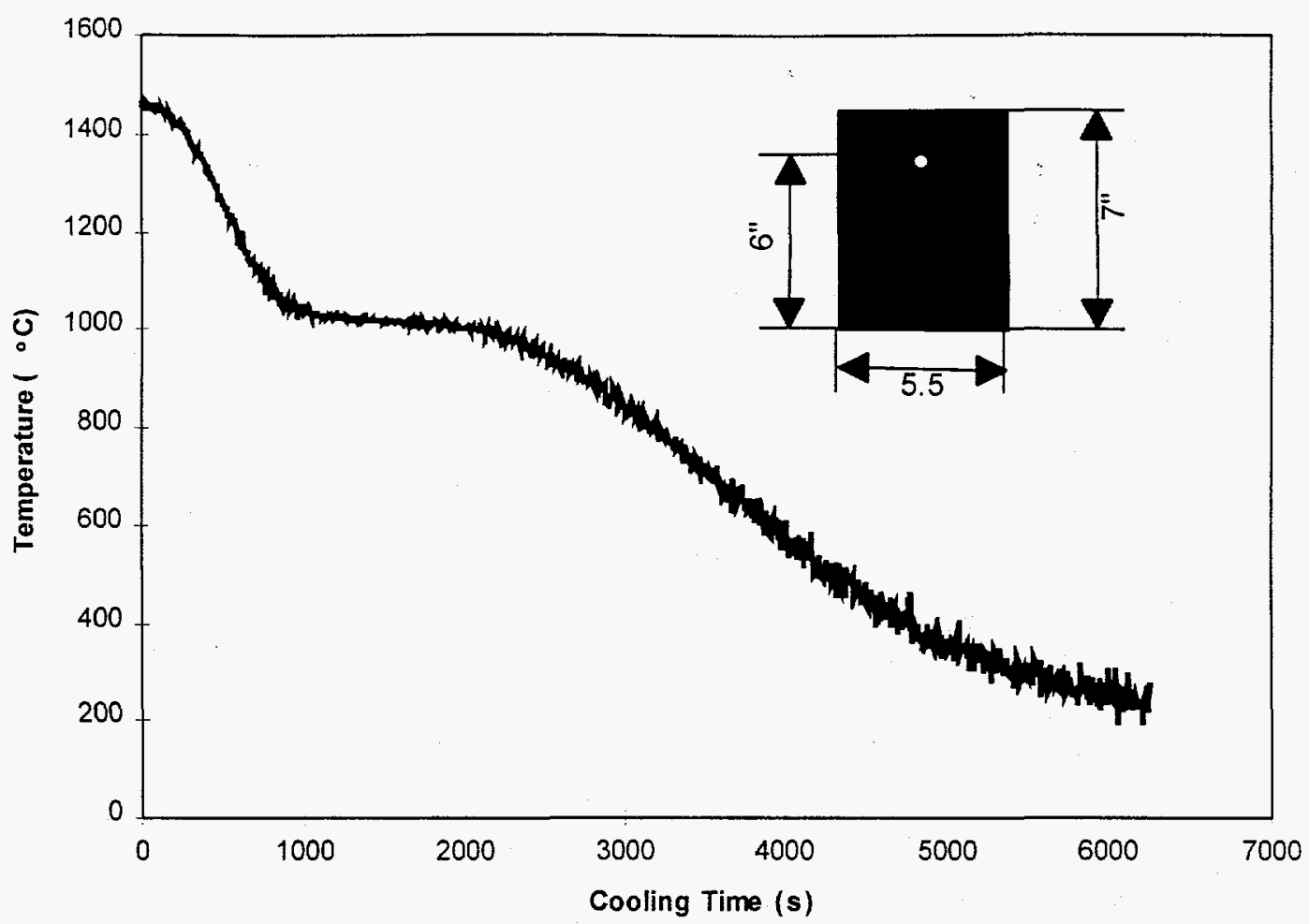

Figure 16. Temperature curve for stainless steel and SRS borosilicate glass mixture solidification test.

After testing both types of glass, the melting temperature was either too high or too low; therefore, another test was conducted using a mixture of the two. This test indicated that by combining the two types of glass, the proper melting temperature and viscosity for the glass phase could be attained. One thermocouple failed when the protection tube cracked. The temperature in the metal phase was measured and is shown in Figure 17. The last test was conducted successfully. Figure 18 shows the temperature history curves at two locations along the centerline within the metal and glass phases, respectively. $\mathrm{T} 1$ indicates the measurement point within the stainless steel, and T2 indicates the point within the glass. 


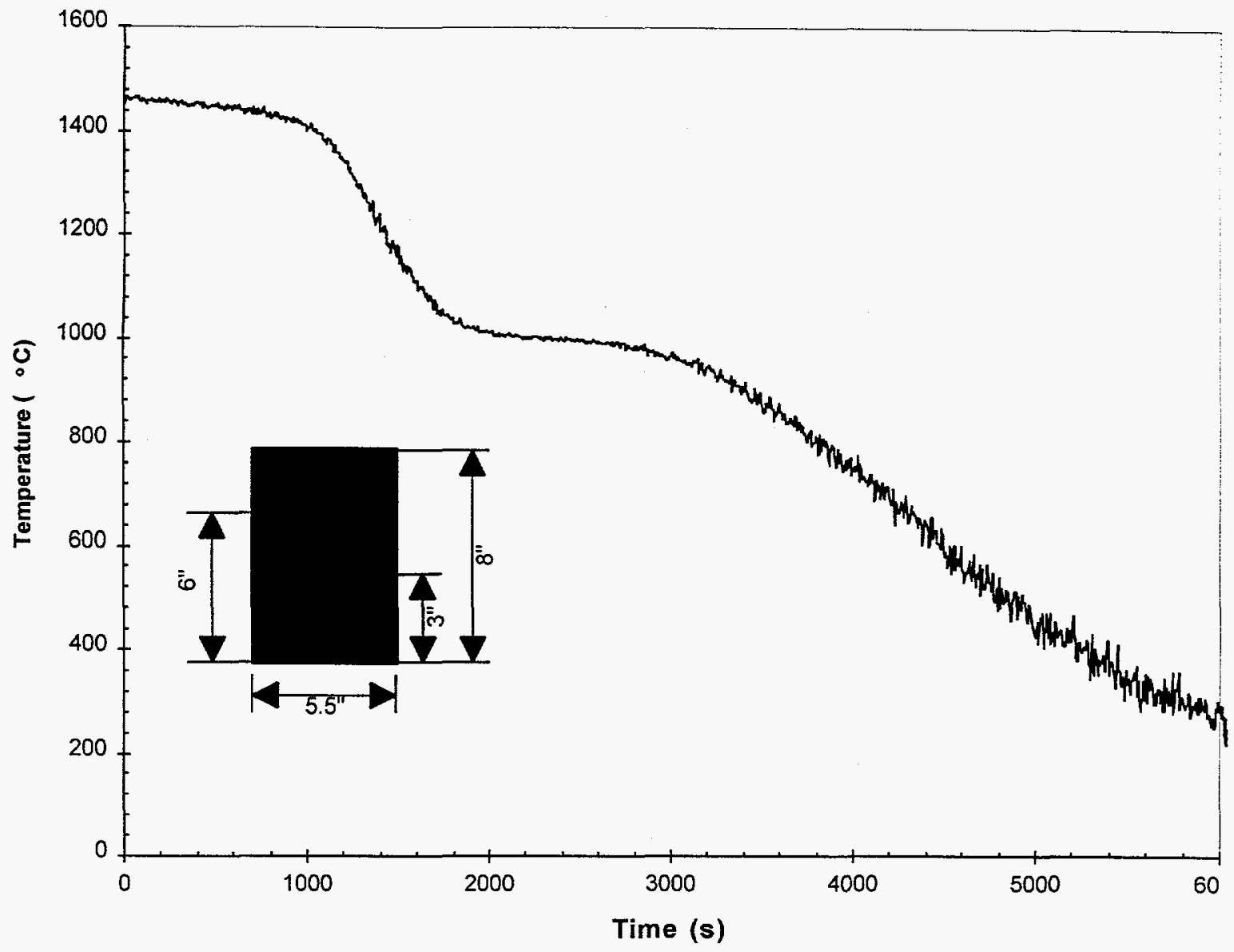

Figure 17. Temperature curve for stainless steel and mixed glass solidification test. 


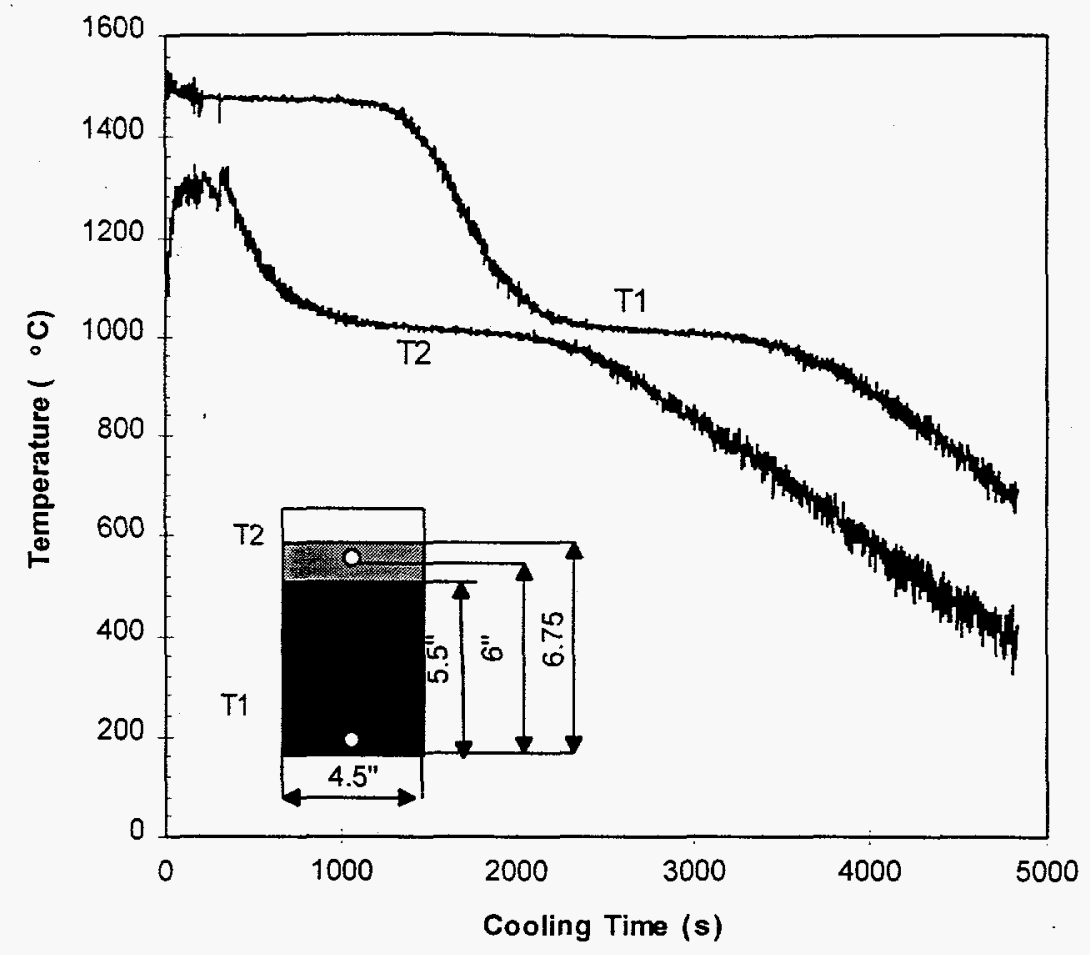

Figure 18. Temperature curves for two different locations during the stainless steel and mixed glass solidification test. 


\section{SIMULATION TESTS OF LIQUID-LIQUID SEPARATION}

The turntable and separator installation for the CS technology demonstration is shown in Figure 19 with the kerosene-water liquids stationary inside the separator. Simulation demonstrations of the CS separation process were conducted and videotaped for the following combinations of two immiscible liquids: water-PLUMR/water-methylene chloride and kerosene-water/kerosenePLUMR. The physical properties of the liquids used in the simulations were measured and are listed in Table 1.

Table 1.

The Properties of the Simulated Liquids

\begin{tabular}{|l|c|c|c|c|c|c|}
\hline Properties & Water & PLUMR & $\begin{array}{c}\text { Methylene } \\
\text { chloride }\left(\mathbf{C H}_{2} \mathbf{C l}_{2}\right)\end{array}$ & Sesame Oil & $\begin{array}{c}\text { Hexane } \\
\left(\mathbf{C}_{6} \mathbf{H}_{12}\right)\end{array}$ & Kerosene \\
\hline $\begin{array}{l}\text { Density } \\
\left(\mathrm{kg} / \mathrm{m}^{3}\right)\end{array}$ & 997.0 & 1306.0 & 1326.6 & 962.74 & 660.3 & 831.7 \\
\hline $\begin{array}{l}\mathrm{Viscosity} \\
\mathrm{kg} /(\mathrm{m} \mathrm{s})\end{array}$ & $0.90275 \times 10^{-3}$ & $\begin{array}{l}\text { non-Newtonian } \\
0.114-0.646\end{array}$ & $<10^{-3}$ & 0.074 & $<10^{-3}$ & $<10^{-3}$ \\
\hline
\end{tabular}

The viscosity of the PLUMR liquid was measured using a Model RI-1-L viscometer manufactured by Rheology International Company. The measurement was conducted using the largest spindle and different rotation speeds. The data are listed in Table 2 . It is evident that PLUMR is a non-Newtonian liquid.

Table 2.

Viscosity of PLUMR

\begin{tabular}{|l|c|c|c|c|c|c|}
\hline Revolutions per minute & 6 & 10 & 12 & 20 & 30 & 50 \\
\hline Viscosity (cp) & $639.6-646$ & $402-425$ & $339-352$ & 234.5 & 169 & 114.5 \\
\hline
\end{tabular}

After the simulation test setup was established, the interface shape of two immiscible liquids under rotation was observed and photographed. Figures 20 and 21 show the interface shapes for the kerosene-water combination at rotating speeds of 155 and 285 revolutions per minute (rpm), respectively. The interface shape shows the geometric advantage of the CS separation-that is, the heavier liquid is pushed toward the outer corner of the separator where it flows out to the container for the heavier fluid. 


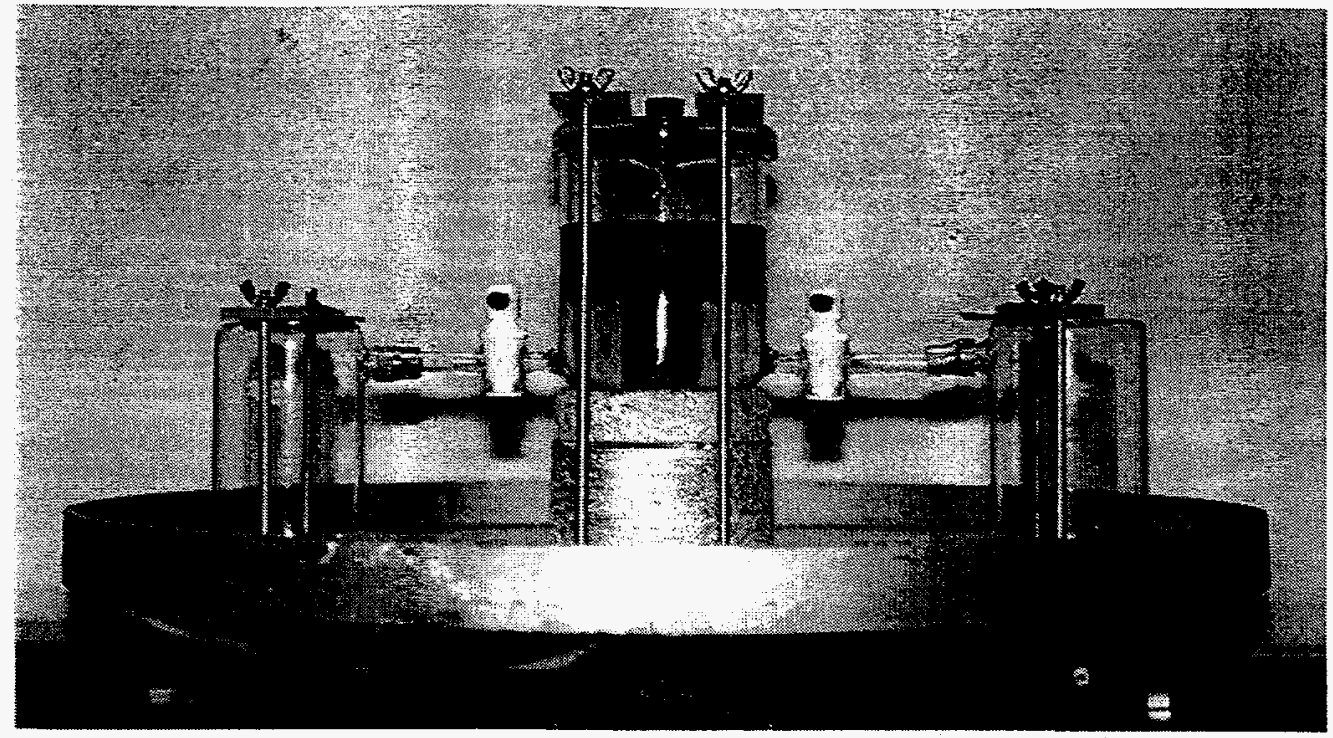

Figure 19. The turntable and demonstration setup with kerosene-water stationary.

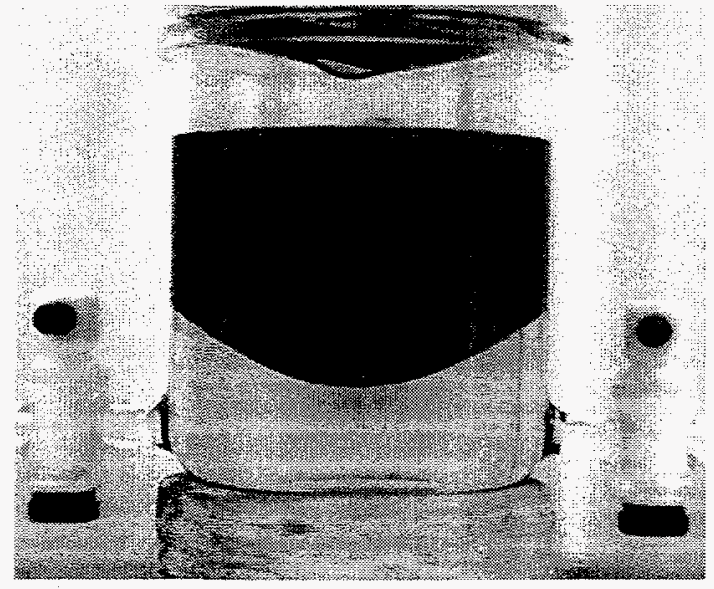

Figure 20. The interface shape of the kerosene-water system with a rotation speed of $155 \mathrm{rpm}$.

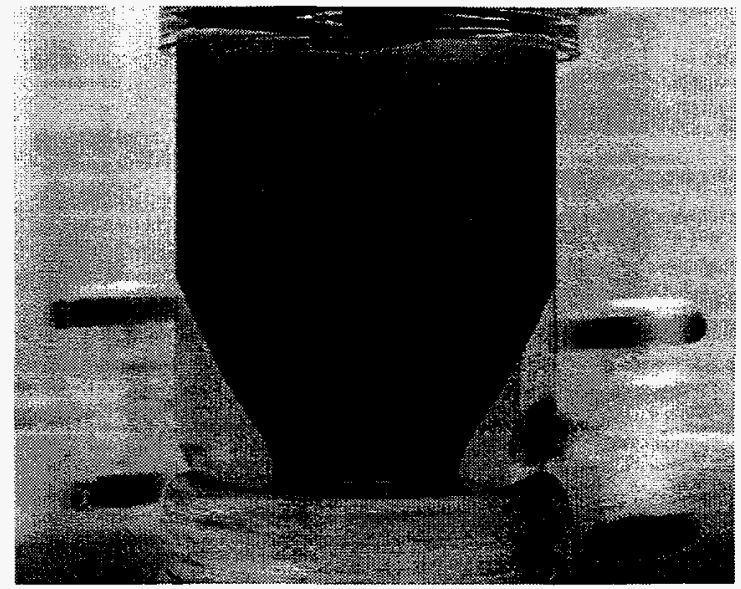

Figure 21. The interface shape of the kerosene-water system with a rotation speed of $285 \mathrm{rpm}$.

The separation efficiencies for different liquid combinations are measured and shown in Figure 22. The results indicate that separation efficiency increases with the rotating speed when it is lower than $300 \mathrm{rpm}$. 


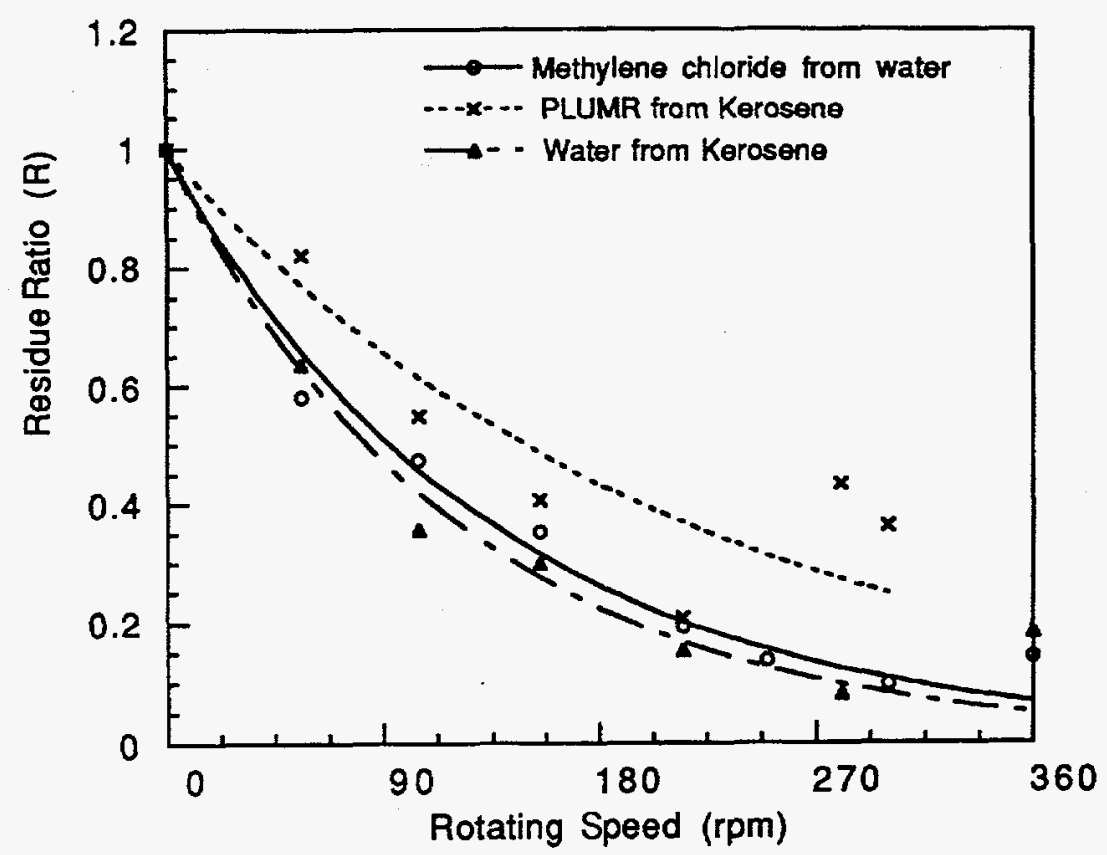

Figure 22. Separation efficiency of CS separation simulation tests.

The simulation tests for the DCS technology have been conducted. Figure 23 shows the setup and some interface shapes of two immiscible liquids in the DCS separator.

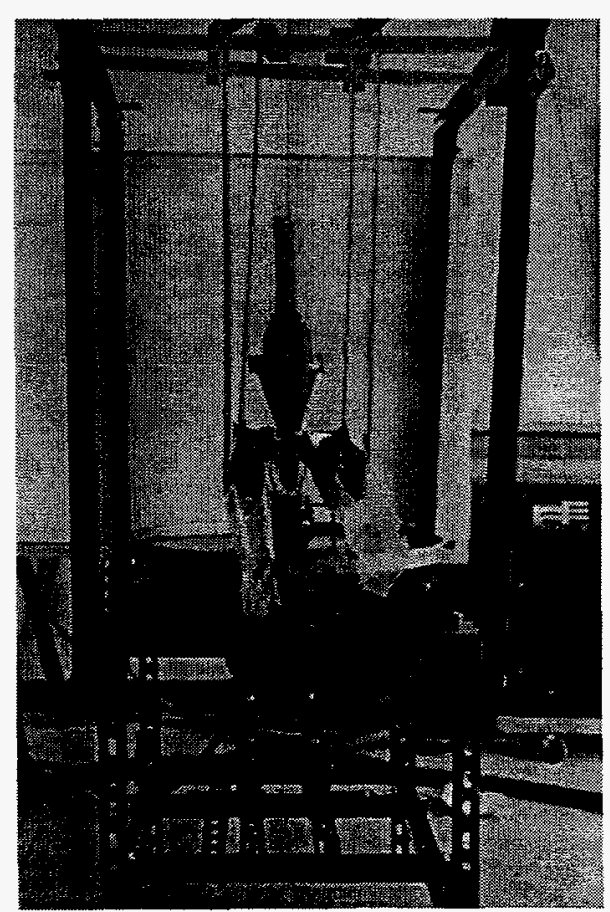

(a) Test setup

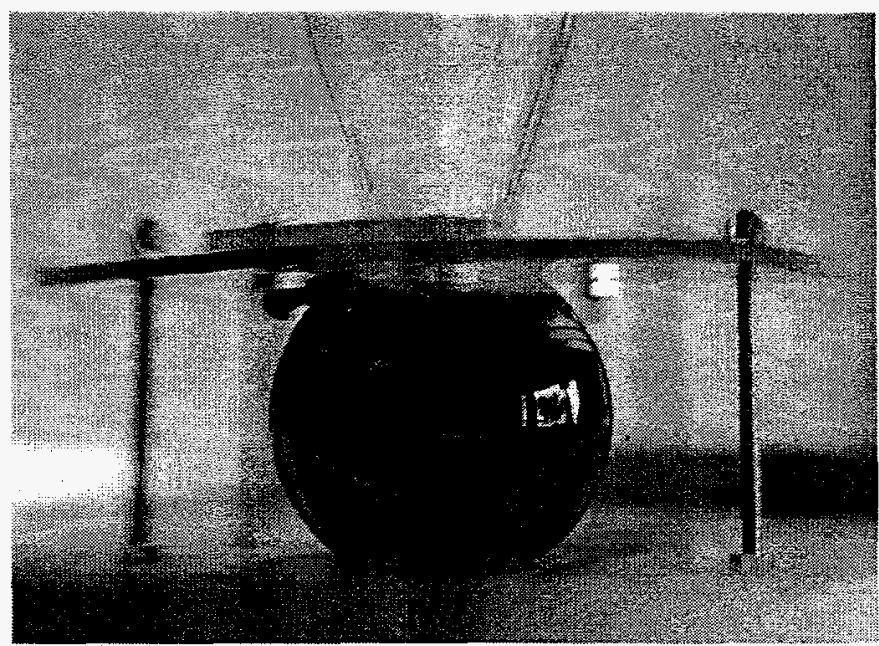

(b) Interface shape (155 rpm)

Figure 23. DCS simulation test setup and interface shapes. 


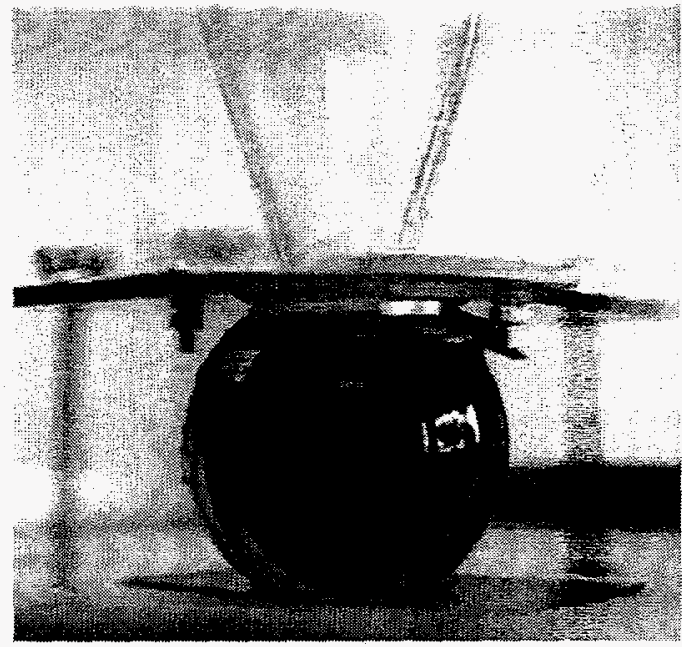

(c) Interface shape (237 rpm)

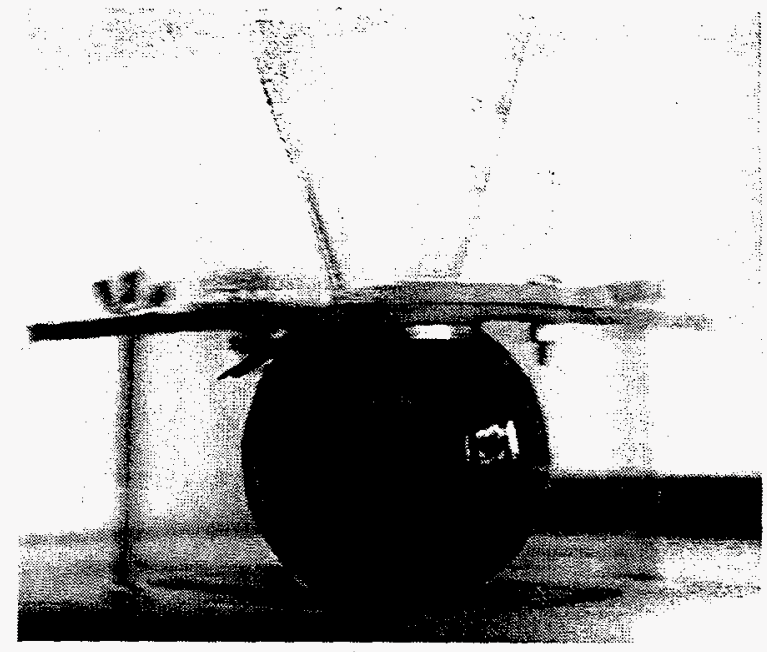

(d) Interface shape (285 rpm)

Figure 23. DCS simulation test setup and interface shapes (Continued).

Analysis of the DCS simulation test data indicates that separation efficiencies of $86 \%$ and $94.6 \%$ were obtained in the water-vegetable oil and PLUMR-oil separation tests, respectively.

The phase distribution and interface shape have been studied for the triangular separator. Figure 24 shows some phase distribution and interface pictures at different rotating speeds using water and kerosene as working liquids.

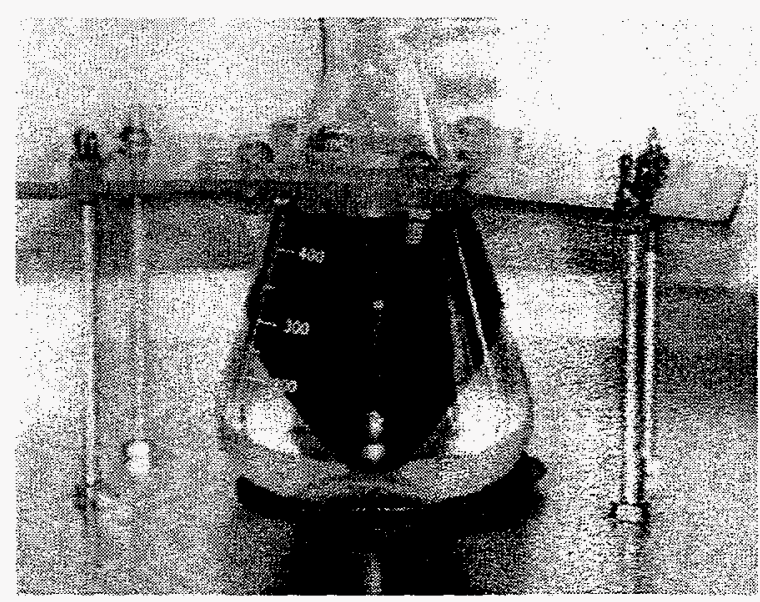

(a) $250 \mathrm{rpm}$

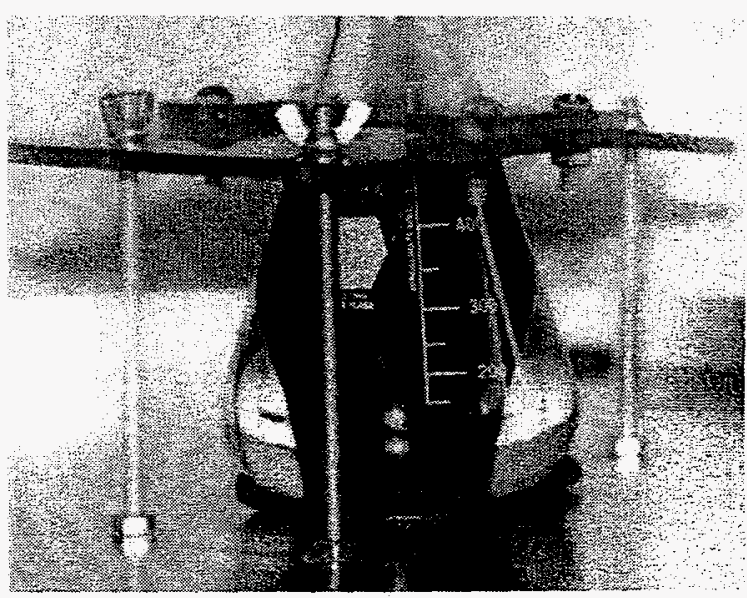

(b) $360 \mathrm{rpm}$

Figure 24. Phase distribution and interface shapes for triangular separator.

One important test, the separation of a liquid-liquid suspension, was successfully demonstrated. Figures 25 through 28 show the separation process. During separation, three liquid layers existed: kerosene, a buffer layer (mixture), and the PLUMR layer, as seen in Figure 27. This 
demonstration verified the fact that centrifugal separation separates the glass inclusions in the molten metal phase.

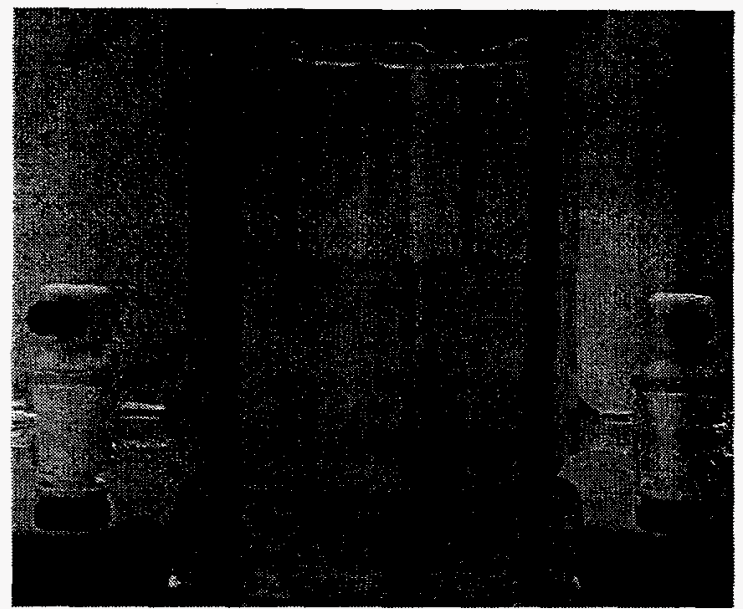

Figure 25. The suspension of kerosene in PLUMR.

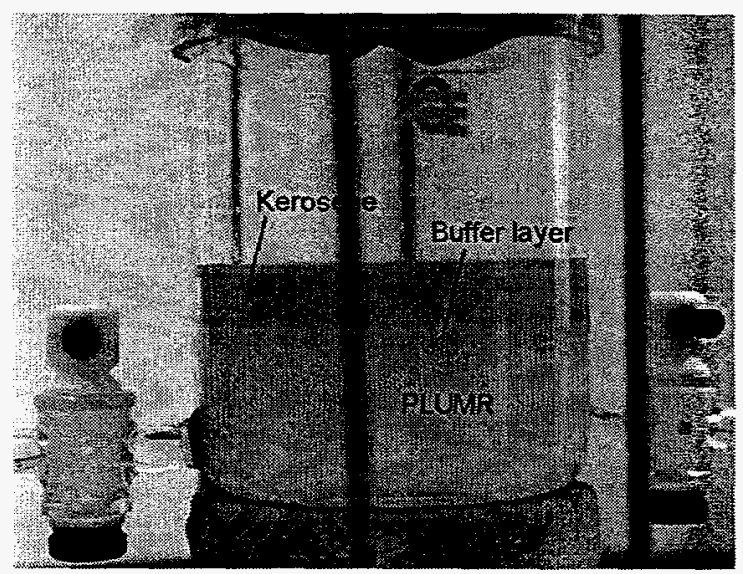

Figure 27. The mid-stage of the suspension separation at ten minutes.

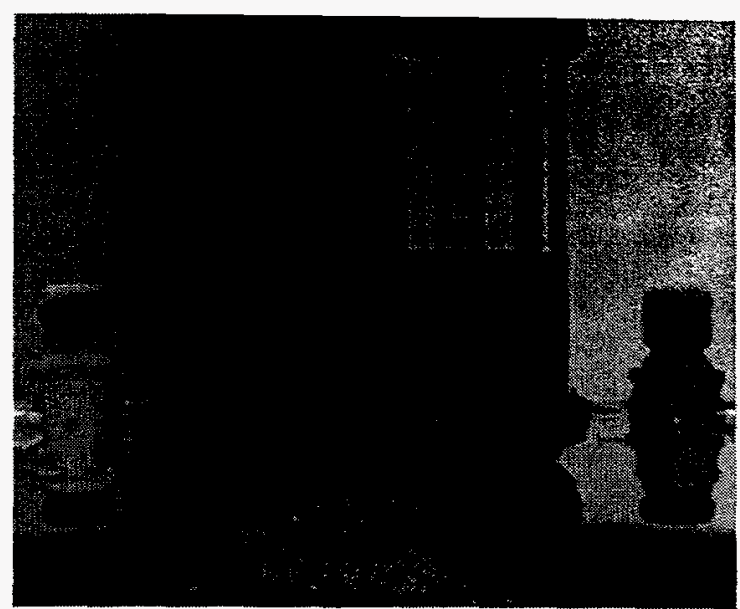

Figure 26. The mid-stage of the suspension separation at five minutes.

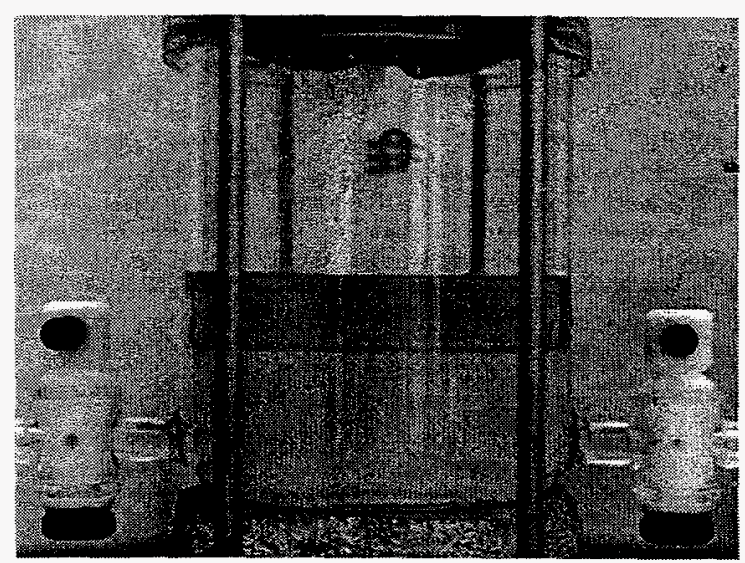

Figure 28. The final phase distribution of the suspension after rotation.

One simulation test for the phase distribution and separation of liquid-liquid suspension using the cylindrical separator has been conducted. Figure 29 shows the results at a speed of $300 \mathrm{rpm}$. 


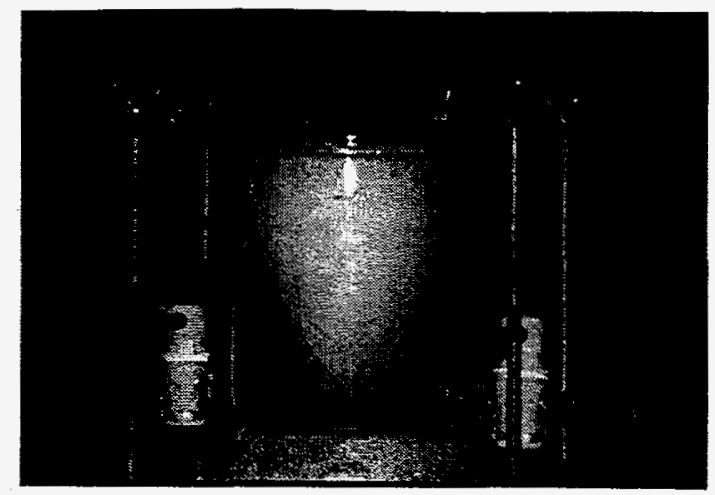

Figure 29. Phase distribution and separation of liquid-liquid suspension using the cylindrical separator. 


\section{NUMERICAL MODELING OF METAL/GLASS PHASE SEPARATION}

\subsection{MATHEMATICAL MODEL AND NUMERICAL METHODS}

The state-of-the-art two-fluid model, which is implemented in the software package Fluent 4.3, has been used in this study. The modeling is based on the following assumptions: (1) a pressure field is shared by both the metal and glass phases; (2) momentum and continuity equations are solved for each phase; (3) the metal and glass are incompressible and have constant density and viscosity; (4) the glass is distributed in the liquid as spherical bubbles with uniform size. The governing equations are summarized below.

The continuity equation is expressed as:

$$
\nabla \cdot\left(\alpha_{p} \bar{U}_{p}\right)=0
$$

Where $\mathrm{p}$ refers to the metal $(\mathrm{m})$ or glass $(\mathrm{g})$ phase.

The momentum equation is:

$$
\begin{gathered}
\alpha_{p} \rho_{p} \frac{D \bar{U}_{p}}{D t}=\nabla \cdot \alpha_{p}\left[\mu_{p} \nabla \bar{U}_{p}-\rho_{p}\left(U_{p}^{\prime} U_{p}^{\prime}\right)\right]-\alpha_{p} \nabla p-\alpha_{p} \rho_{p} G+\mathrm{K}\left(\bar{U}_{p}-\bar{U}_{q}\right) \\
\mathrm{p}=\mathrm{m}, \quad \mathrm{g} \text { and } \mathrm{q}=\mathrm{m}, \quad \mathrm{g}(\mathrm{p}=\mathrm{q})
\end{gathered}
$$

Where $\mathrm{K}$ denotes the interphase momentum exchange coefficient and $\mathrm{G}$ represents gravity force.

The constituate equations for volume fractions can be expressed as follows:

$$
\begin{gathered}
\alpha_{\mathrm{m}}+\alpha_{\mathrm{g}}=1 \\
\nabla \cdot\left(\alpha_{\mathrm{g}} \overline{\mathrm{U}}_{\mathrm{g}}\right)=0
\end{gathered}
$$

Based on assumption 4 , the exchange coefficient is determined by the following equation:

$$
\mathrm{K}=\frac{3}{4} C_{D} \alpha_{g} \frac{\rho_{m}\left|\bar{U}_{m}-\bar{U}_{g}\right|}{d}
$$

The drag coefficient, $\mathrm{CD}$, in Equation 5 is a function of the Reynolds number, Re:

$$
\begin{array}{cc}
C_{D}=\frac{24}{\operatorname{Re}\left(1+0.15 \operatorname{Re}^{0.687}\right)} \quad & \operatorname{Re} \leq 1000 \\
C_{D}=0.44 & \operatorname{Re}>1000
\end{array}
$$




$$
\operatorname{Re}=\rho_{m} \frac{\left|\bar{U}_{m}-\bar{U}_{g}\right|}{\mu_{m}} d
$$

\subsection{PhASE DISTRIBUtion RESULtS}

In the numerical analysis, it is assumed that the glass is uniformly distributed in the metal phase as spherical droplets before separation. Four cases have been run with three glass contents-2\%, $5 \%$, and $10 \%$-and two rotating speeds- $300 \mathrm{rpm}$ and $150 \mathrm{rpm}$. The results of the glass volume fraction distribution are presented in Figures 30 and 31.

In Figure 30, the right and left halves are the results of the cases with glass contents of $2 \%$ and $5 \%$, respectively, with the same rotating speed of $300 \mathrm{rpm}$. Figure 31 shows the results for the cases with $10 \%$ glass content and with rotating speeds of $150 \mathrm{rpm}$ and $300 \mathrm{rpm}$ on the right and left halves, respectively.

From the figures, it can be seen that, at the lower glass content percentages (2\% and $5 \%$ ), the glass phase cannot be separated from the metal phase and that the two phases are separated more clearly for the higher glass content percentage $(10 \%)$. Figure 31 shows that at the high glass content percentage, more glass phase locates in the center of the crucible at the higher rotating speed than for the lower rotating speed. This point implies that high speed cannot be applied for the DCS method; otherwise, the heavier phase may be pushed out first instead of the lighter phase by the plunger movement.
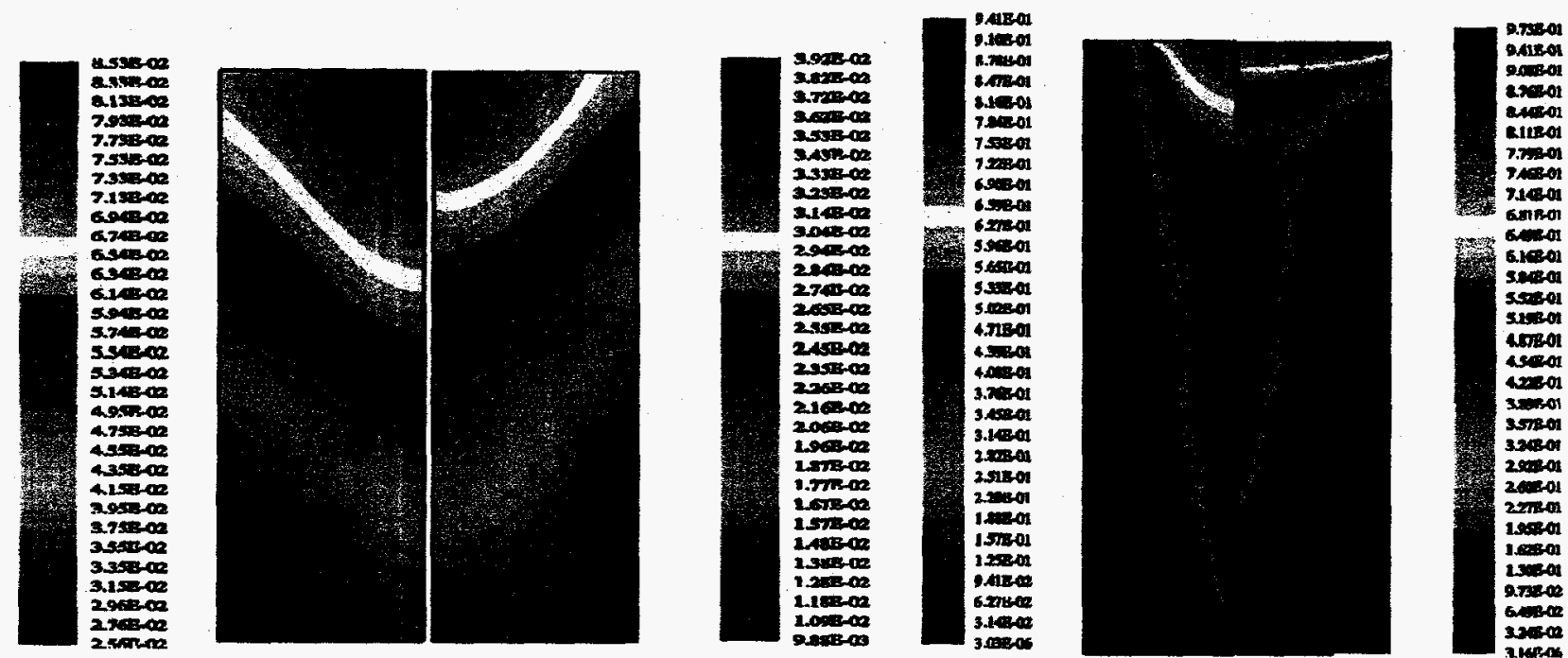

Figure 30. Glass volume fraction distribution for the cases of $2 \%$ (left) and $5 \%$ (right) glass content with a rotating speed of $300 \mathrm{rpm}$.

Figure 31. Glass volume fraction distribution for the case of $10 \%$ glass content with rotating speeds of $150 \mathrm{rpm}$ (left) and $300 \mathrm{rpm}$ (right). 


\section{MOLTEN METAL/GLASS PHASE SEPARATION EXPERIMENTS}

The experimental setup for the molten stainless steel/glass phase separation includes an adjustable motor, a turntable, and a flange crucible fixture. The photos of the crucible assembly and system are shown in Figures 32 and 33.

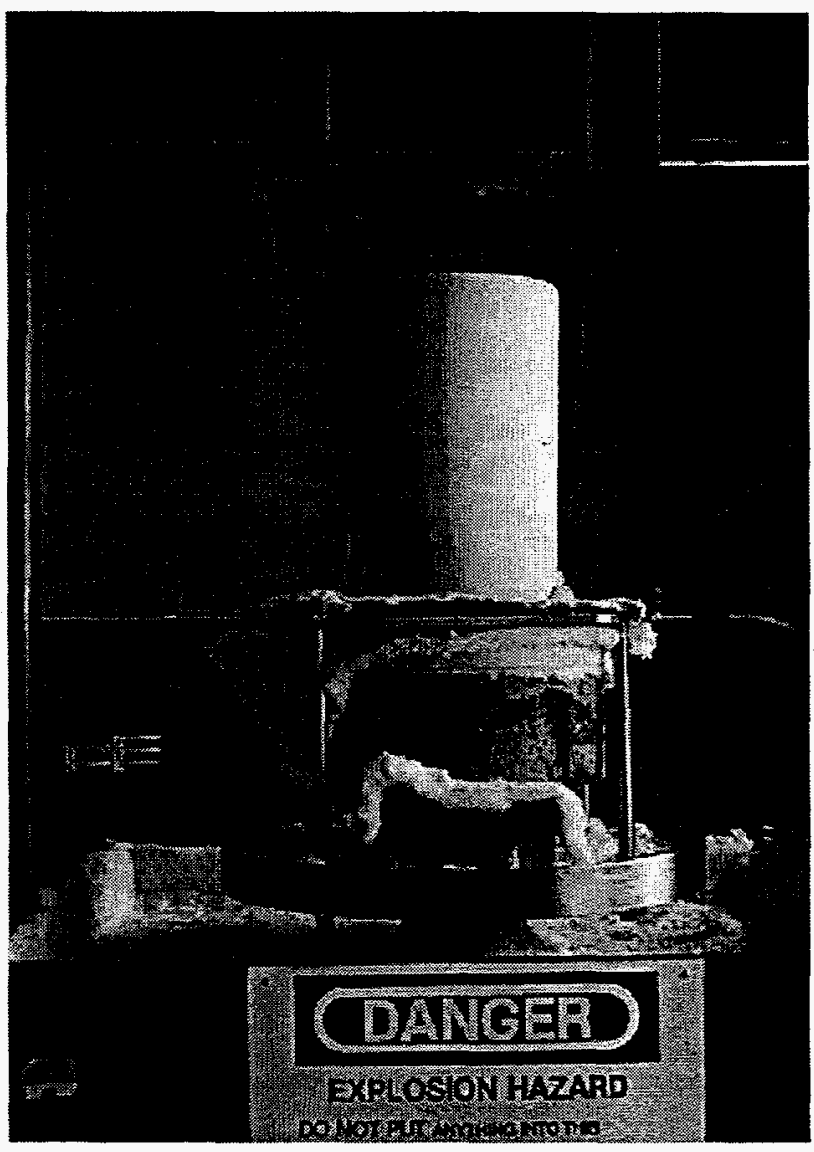

Figure 32. Flange crucible assembly.

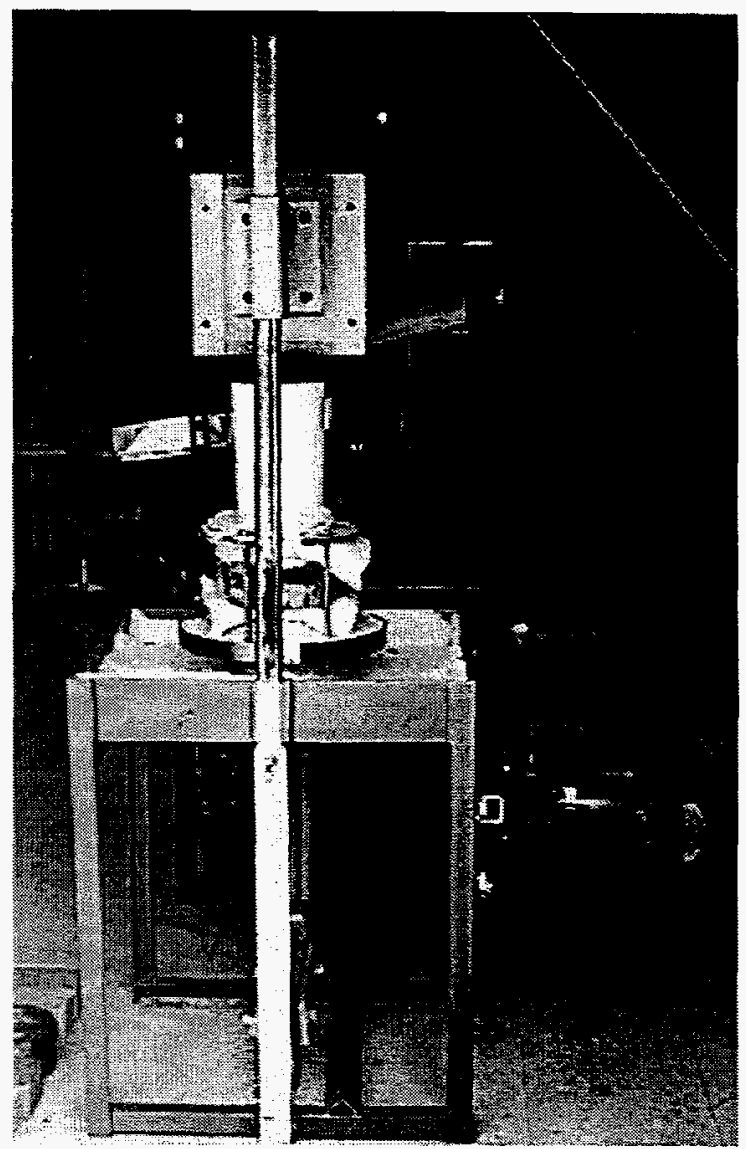

Figure 33. Molten metal/glass phase separation test setup.

After initial setup testing, one test of phase separation was conducted. In the test, $9.9 \mathrm{~kg}$ stainless steel, $0.473 \mathrm{~kg}$ SRS waste borosilicate glass, and $0.473 \mathrm{~kg}$ commercial borosilicate glass were used as the raw mixture. The rotation speed was $150 \mathrm{rpm}$.

The final phase states are shown in Figure 34. Two distinguishable phases can be observed. After removing the glass phase, the metal phase ingot is shown in Figure 35. A clear and clean boundary exists. 


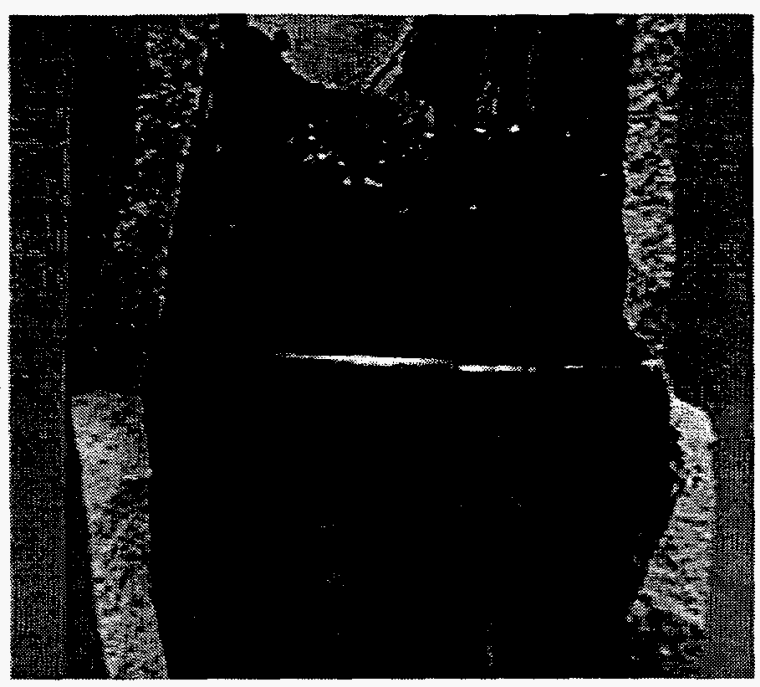

Figure 34. Final phase states after melting, rotating and solidification.

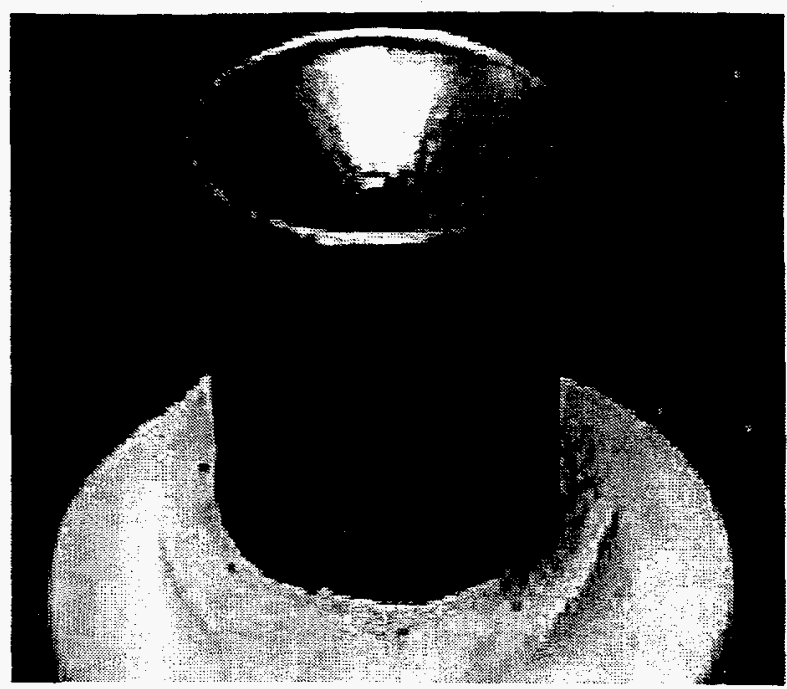

Figure 35. Metal phase ingot and the interface shape (150 rpm).

The interface was measured and plotted in Figure 36.

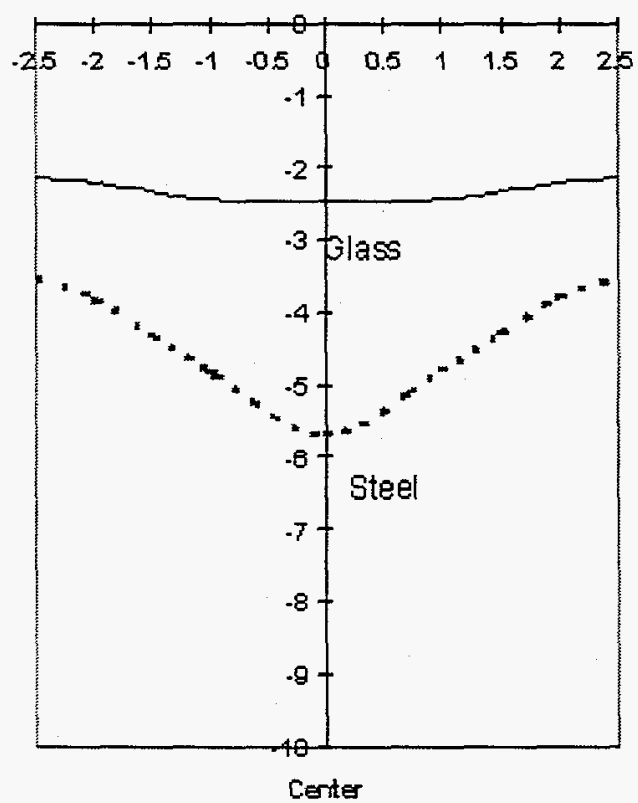

Figure 36. Free surface and interface shape. 


\section{CONCLUSION}

This project's completed tasks can be summarized in four phases-the melting and solidification experiments on metal, glass, and metal/glass mixtures; the simulation test of the separation process; the numerical modeling of metal solidification and phase separation; and the molten glass/metal phase distribution and separation. After examining the results, the following was noted:

1. The melting/solidification tests for stainless steel and aluminium have been conducted.

- The magnetic elevation for the aluminium induction melting was observed.

- The temperature history and distribution were measured during the solidification processes.

- The solidification rates were evaluated. The solidification rates for aluminum are faster than those for stainless steel.

- In the solidification tests, the temperature gradient was much higher along the central line than along the radius.

2. The melting/solidification tests for two kinds of borosilicate glass-commercial borosilicate glass and SRS waste glass- have been conducted.

- SRS glass has a much lower melting temperature and viscosity than the commercial borosilicate glass.

- The temperature history and distribution were measured in the solidification tests.

3. Several melting tests for stainless steel and glass mixtures have been conducted. We found that a clear interface boundary exists between the metal and glass phases. The mixture of equal parts of the two kinds of glass has the proper melting point for melting with the stainless steel.

4. The simulation tests for the CS and the DCS technologies have been completed for four combinations of two immiscible liquids and a liquid suspension.

- The separation efficiency for the CS technology was measured. The results indicate that separation efficiency increases with the rotating speed when the rotating speed is lower than $300 \mathrm{rpm}$.

- During suspension separation, three liquid layers exist: a lower density liquid layer, a buffer layer (mixture), and a higher density liquid layer.

- The suspension separation demonstration also verified that centrifugal force can separate the glass inclusions from the molten metal phase. 
5. Numerical studies have been conducted for molten iron and aluminium solidification and molten metal and glass phase separation in rotating crucibles.

- The solidification pattern, flow pattern, and temperature field were predicted and analyzed at different cooling conditions for iron and aluminium.

- The phase distribution results for phase separation modeling indicate that, at the lower glass content percentages ( $2 \%$ and $5 \%$ ), the glass phase cannot be clearly separated from the metal phase. The two phases separate more clearly for the high glass content percentage $(10 \%)$.

- At the high glass content percentage, more glass phase locates in the center of the crucible at higher rotating speeds versus lower rotating speeds.

6. The molten metal/glass phase separation test indicates that the molten glass and metal phases can be separated by centrifugal forces. A very clear and clean interface exists. 
Cotchen, J.K. and Davis, H.F., 1992. Electric Arc Furnace Processing of Solid Waste, presented at the International Symposium, Process of Residues and Effluents, TMS Annual Meeting.

Enokizono, M., Todaka, T., Yokoji, K., Wada, Y., and Matsumoto, I., May 1995, "ThreeDimensional Moving Simulation of Levitation-Melting Method," IEEE Transactions on Magnetics, Vol. 31, No. 3, Part 1, pp. 1870-1872.

Gillins, R.L. and Poling, S.D., May 1994, "Plasma Hearth Waste Treatment Demonstration for Radioactive Mixed Waste," International Incineration Conference Proceedings.

Grozhik, V. A., Bychko, G.V. and Khodskij, L. G., 1992, "Effect of Additives on Properties of Lead-Borosilicate Glasses and Thin-Film Coatings on their Basis," Steklo Keram, No. 2, pp. 25-27.

Gupta, R., Mauri, R., and Shinnar, R., 1996, "Liquid-Liquid Extraction Using the CompositionInduced Phase Separation Process," Ind. Eng. Chem. Res., Vol.35, pp.2360-2368.

Hassel, G.R., Geimer, R.M., Batdorf, J.A., and Leatherman, G.L., May 1994, "Evaluation of the Plasma Hearth Process for Mixed Waste Treatment Applications," International Incineration Conference Proceedings.

Idaho National Engineering Laboratory (INEL), 1994, "Plasma Hearth Process Technology Development Project," Fiscal Year 1994 Year-End Report, INEL, Idaho Falls.

Kawamura, K. and Ohuchi, J., 1995, "Characterization of Highly Waste Loaded Glass for HLW," Materials Research Society Symposium Proceedings, Vol. 353, No. 1, pp. 87-93.

Lakomskii, V.V., Marinskii, G.S., Bogachenko, A.G., Medovar, B.I., Sysonov, A.M., Zagatnyi, L.S., and Dregolyunk, V.I., 1985, "Separation of the Slag-Metal Emulsion and Removal of Liquid Non-Metallic Inclusions From Metal in the Field of Centrifugal Forces," Problems Spetsial'noi Elektrometallurgii, Vol. 1, No. 2, pp. 15-19.

Nemec, L., 1994, "Analysis and Modelling of Glass Melting," Ceramics - Silikaty, Vol. 38, No. 1, pp. 45-58.

Nishioka, M., Hirai, S., and Yanagisawa, K., 1990, "Solidification of Glass Powder With Simulated High-Level Radioactive Waste During Hydrothermal Hot-Pressing," Journal of the American Ceramic Society, Vol. 73, pp. 3173-22.

Office of Environmental Management and Technology Development, 1995, Mixed Waste Characterization, Treatment, and Disposal Focus Area, United States Department of Energy - Office of Environmental Management, DOE/EM-0252.

Office of Environmental Management and Technology Development, 1995, Technology Catalogue, United States Department of Energy - Office of Environmental Management. 
Purohit, A., Webster, S., and Johnson, A., 1995, "Plasma Hearth Process Slag Chemistry and Slag/Metal Processing," Mixed Waste Characterization, Treatment, and Disposal Focus Area, Office of Environmental Management and Technology Development, pp. 14-15.

R.C. Xin, Y.Z. Liu, K. Sundaram, Z.F. Dong, and M.A. Ebadian, November 1997, "LiquidLiquid Centrifugal Separation for Molten Metal/Slag System - Simulation Test and Numerical Study," X-Change 97, Miami, Florida.

Robatel Group, March/April 1993, Advanced Centrifuges for Solid-Liquid Separation and Liquid-Liquid Extraction, Filtration \& Separation, pp.104-106.

Scholze, H., 1991, Glass-Nature, Structure, and Properties, Springer-Verlag, New York.

Science Applications International Corporation (SAIC), 1994, Plasma Hearth Metal/Slag Separation Testing, ANL RFP No. 94-60ML-18.

Skrovankova, D., Bennerova, L., and Hlavac, J., 1993, "Vitrification of Simulated IntermediateLevel Waste from Nuclear Power Plants I. Melting Behavior and Properties of Selected Glasses," Ceramics - Silikaty, Vol. 37, No. 1, pp. 49-55.

Smith, P.A., Vienna, J.D., and Hrma, P., 1995, "Effects of Melting Reactions on LaboratoryScale Waste Vitrification," Journal of Materials Research, Vol. 10, No. 8, pp. 21372149.

Tomozawa, M. and Doremus, R.H., 1985, Treatise on Materials Science and Technology, Glass IV Vol. 26, Academic Press, Orlando.

Viskanta, R., 1994, "Review of Three-Dimensional Mathematical Modeling of Glass Melting," Journal of Non-Crystalline Solids, Vol. 177, Part 1, pp. 347-362.

Wang, C.Y. and Beckermann, C., 1994, "Multi-Scale/-Phase Modeling of Dendritic Alloy Solidification, Transport Phenomena in Solidification," American Society of Mechanical Engineers, Heat Transfer Division, Publication HTD Vol. 284, ASME, New York, pp. 75-95.

Warr, G.G., Zemb, T.N., and Drifford, M., 1990, "Liquid-Liquid Phase Separation in Cationic Micellar Solutions," J. Phys. Chem., Vol.94, pp. 3086-3092.

Winegard, W.C. and Cole, G.S., 1964, "Thermal Convection During Horizontal Solidification of Pure Metals and Alloys," Journal Institute of Metals, Vol.93, pp. 153-164.

Wolff, F. and Viskanta, R., 1988, "Solidification of a Pure Metal at a Vertical Wall in the Presence of Liquid Superheat," International Journal of Heat and Mass Transfer, Vol.14, pp. 245-253.

Wu, Y. and Lacroix, M., 1993, "Numerical Study of Melting of Scrap Metal," Numerical Heat Transfer: An International Journal of Computation and, Methodology; Part A: Applications, Vol. 24, No. 4, pp. 413-425. 


\section{SYSTEM OPERATING PROCEDURES}

The following are the main steps for operating the system:

1. Before opening any water valves or turning on any electrical switches, check the entire system. The check list includes the chilled water line pressure, the closed loop cooling water pressure (also check the quality of the water inside the loop monthly), the power lead connections from the power unit to induction coil, and any metal equipment (e.g., tools) near the power lead and furnaces.

2. Because of the strong magnetic field around the induction coil, remove all unnecessary meters, diskette, watches, and other items which may be influenced by a magnetic field;

3. Turn on the breaker for the main power supply;

4. Set up the cooling system. This consists of the following three steps (see Figure 1 for the valve locations):

- Before starting the pump, check all valves. Valves B.V1, B.V2, G.V1, G.V2, S.V2 are normally open, and G.V3, G.V4, B.V3, B.V4, S.V1 are closed. (See the attached water cooling system drawing at the end of this section).

- Open B.V3 and B.V4. Turn on the closed loop water pump and the chilled water cycling pump. Then, the water system is in working condition. If the temperature of the cycling water is too high, the thermostat will send signals to S.V1 and S.V2 to open S.V1 and close S.V2 automatically. As a result, chilled water will flow through the heat exchanger, decreasing the temperature of the closed loop water to keep the power unit and induction coil in proper working condition.

- Check the pressure drop in the closed loop and the chilled water loop to verify whether the flow is normal.

5. Turn on the power unit;

6. Hit the reset button on the control panel to turn off the ground lights;

7. To reset the ground auxiliary interface, push the stop button and hit the reset button again;

8. Adjust the power percentage to the lowest position;

9. Set the timer for the time of operation;

10. Press the green button to start the furnace;

11. Adjust the power output percentage according to the load and crucible condition. (Note that about 20 percent output power can keep the charge in molten state if it has been melted.); 
12. If the operation is completed, or if there is an emergency, or operation needs to be temporarily stopped, hit the STOP button, which is the RED button on the panel;

13. After finishing the melting operation, keep the cooling system running for about half hour and make sure the induction coil is cooled down;

14. When no cooling is needed, turn off the pumps. Close B.V3 and B.V4;

15. In case of an emergency (electrical power off), close G.V2 and B.V2 and open G.V3 and G.V4. Tap water will cool the power supply and the coil for some time. Then close G.V3 and G.V4.

16. Fill out the equipment use log. Record any abnormalities or problems. Sign the log.

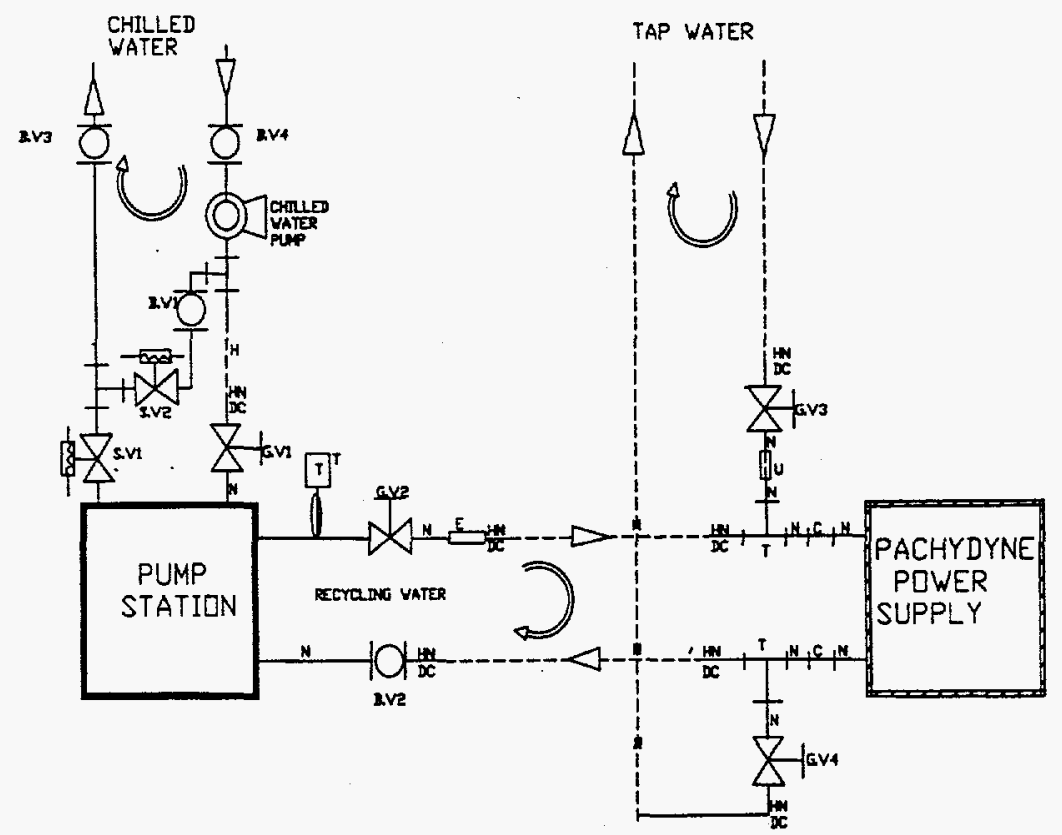

B.V: Ball valve, G.V: Gate valve, HN: Hose nipple, $\mathrm{DC}$ : Worm drive clamp, $H$ : Hose $\mathrm{N}$ : Nipple, E: Elbow, U: Union, C: Coupling, P: Pipe, SiV: Solenoid valve, T: Thermostat

Water cooling system. 